\title{
Italian Association of Clinical Endocrinologists (AME) and International Chapter of Clinical Endocrinology (ICCE). Position statement for clinical practice: prolactin-secreting tumors
}

\author{
Renato Cozzi', Maria Rosaria Ambrosio², Roberto Attanasio ${ }^{3}{ }^{3}$, Claudia Battista4, Alessandro Bozzao5, \\ Marco Caputo6 ${ }^{6}$ Enrica Ciccarelli7, Laura De Marinis ${ }^{8}$, Ernesto De Menis ${ }^{9}$, Marco Faustini Fustini ${ }^{10}$, \\ Franco Grimaldi ${ }^{11}$, Andrea Lania' ${ }^{12}$, Giovanni Lasio ${ }^{13}$, Francesco Logoluso ${ }^{14}$, Marco Losa ${ }^{15}$, Pietro Maffei ${ }^{16}$, \\ Davide Milani ${ }^{13}$, Maurizio Poggi ${ }^{17}$, Michele Zini ${ }^{18}$, Laurence Katznelson ${ }^{19}$, Anton Luger20 and Catalina Poiana ${ }^{21}$ \\ on behalf of AME
}

\begin{abstract}
${ }^{1}$ Division of Endocrinology, Niguarda Hospital, Milan, Italy, ${ }^{2}$ Section of Endocrinology and Internal Medicine, Department of Medical Sciences, University of Ferrara, Ferrara, Italy, ${ }^{3}$ AME Scientific Committee, Milan, Italy, ${ }^{4}$ Endocrinology Unit, IRCCS Casa Sollievo della Sofferenza Hospital, San Giovanni Rotondo (FG), Italy, ${ }^{5}$ Neuroradiology, S. Andrea Hospital, NESMOS Department (Neuroscience, Mental Health, Sensorial Organs), Sapienza University of Rome, Rome, Italy, ' Laboratorio Analisi Cliniche e Microbiologia, Synlab SRL, Calenzano, Florence, Italy, ${ }^{7}$ Endocrinology, Ospedale Martini, ASL Città di Torino, Turin, Italy, ${ }^{8}$ Pituitary Unit, Department of Endocrinology, Catholic University of the Sacred Heart, School of Medicine, Rome, Italy, 9 Internal Medicine 2, Treviso Hospital, Treviso, Italy, ${ }^{10}$ IRCCS Istituto delle Scienze Neurologiche di Bologna, Bologna, Italy, ${ }^{11}$ AME President, Endocrinology and Metabolism Unit, University Hospital S. Maria della Misericordia, Udine, Italy, ${ }^{12}$ Department of Biomedical Sciences, Endocrinology Unit, Rozzano, Italy, ${ }^{13}$ Department of Neurosurgery, Humanitas Clinical and Research Center IRCCS, Rozzano, Italy, ${ }^{14}$ Endocrinology Unit, Bisceglie Hospital, ASLBT, Bisceglie, Italy, ${ }^{15}$ Department of Neurosurgery and Gamma Knife Radiosurgery, IRCCS San Raffaele Scientific Institute, Vita-Salute University, Milan, Italy, ${ }^{16}$ Department of Medicine (DIMED), 3rd Medical Clinic, Padua University Hospital, Padua, Italy, ${ }^{17}$ Endocrinology, Department of Clinical and Molecular Medicine, S. Andrea Hospital, Sapienza University of Rome, Rome, Italy, ${ }^{18}$ Endocrinology Unit, Azienda Ospedaliera S. Maria Nuova IRCCS, Reggio Emilia, Italy, ${ }^{19}$ Department of Medicine, Stanford University Hospital, Stanford, CA, USA, ${ }^{20}$ Division of Endocrinology and Metabolism, Medical University of Vienna, Vienna, Austria, and ${ }^{21}{ }^{1} \mathrm{Carol}$ Davila' University of Medicine and Pharmacy - Endocrinology, "C.I. Parhon" National Institute of Endocrinology - Pituitary and Neuroendocrine Disorders, Bucharest, Romania
\end{abstract}

This document reflects the state of the art at the time of publication and it aims to standardize clinical practice. We encourage medical professionals to always use this information in conjunction with their best clinical judgment as the presented recommendations may not be appropriate in all situations. Any decision by practitioners must be made in light of local resources and individual patient circumstances.

Correspondence should be addressed to R Cozzi Email dr.renatocozzi@gmail.com

\begin{abstract}
Prolactinomas are the most frequent pituitary adenomas. Prolactinoma may occur in different clinical settings and always require an individually tailored approach. This is the reason why a panel of Italian neuroendocrine experts was charged with the task to provide indications for the diagnostic and therapeutic approaches that can be easily applied in different contexts. The document provides 15 recommendations for diagnosis and 54 recommendations for treatment, issued according to the GRADE system. The level of agreement among panel members was formally evaluated by RAND-UCLA methodology. In the last century, prolactinomas represented the paradigm of pituitary tumors for which the development of highly effective drugs obtained the best results, allowing to avoid neurosurgery in most cases. The impressive improvement of neurosurgical endoscopic techniques allows a far better definition of the tumoral tissue during surgery and the remission of endocrine symptoms in many patients with pituitary tumors. Consequently, this refinement of neurosurgery is changing the therapeutic strategy in prolactinomas, allowing the definitive cure of some patients with permanent discontinuation of medical therapy.
\end{abstract} Printed in Great Britain

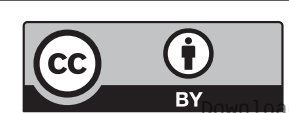

This work is licensed under a Creative Commons Attribution 4.0 International License. 


\section{Introduction}

\section{1.a. Why this document}

Prolactinomas are the most prevalent pituitary tumors. Medical therapy with dopamine agonists (DA) has been considered as the first-line treatment for relieving symptoms, normalizing hyperprolactinemia, and reducing tumor size in the majority of patients, whereas surgery as a second-line treatment indicated only for the minority of patients showing resistance or intolerance to DA, for patients with pituitary apoplexy, or based on patient's preference (1). Technical advances have improved surgical outcome, obtaining total removal of the tumor, high rate of disease remission, and sparing normal pituitary function (2). Thus, the improvement of surgery could change in some prolactinomas the paradigm of DA chronic treatment as a first-line therapeutic strategy.

Prolactinoma is a clinical entity that includes different parameters: micro- and macroadenoma, males and females, patients with fertility consideration or postmenopausal, children or elderly patients, sensitivity or resistance to DA, presence of mass effect, and aggressive behavior (3). An individually tailored treatment is thus needed to manage a wide variety of settings, including the drawbacks of DA treatment in patients with psychiatric diseases.

To discuss all these aspects, a group of Italian experts has gathered together their clinical experience on the diagnostic and therapeutic challenges of prolactinoma patients, aiming to better define the most updated clinical approach and therapeutic options. Panelists were selected by the endorsing scientific societies (AME and ICCE) and included 15 endocrinologists with skill in the management of pituitary diseases (one skilled in scientific methodology), two neurosurgeons skillful in pituitary surgery and working in a high-volume pituitary center, one expert of laboratory medicine, and one neuroradiologist.

\section{1.b. Methodology}

Literature scanning has been performed in Pubmed via the MeSH terms coupled with free-text search. Bibliographic research has been completed using the similar articles function and following the authors of the most relevant publications. No filter has been selected for article type, publication date, language, or journal.

The grading of recommendations, assessment, development, and Eealuation (GRADE) system was adopted for the present position statement $(4,5,6)$. In accordance with GRADE, evidence is categorized into four quality levels (high, moderate, low, or very low), while recommendations are classified as strong ('recommendations') or weak ('suggestions'), on the basis of the quality of supporting evidence and level of agreement between the panel members (5). Whenever possible, the level of evidence (LoE) is reported in Table 1 using the following symbols: very low quality $(\otimes \bigcirc \bigcirc)$ ), low $(\otimes \otimes \bigcirc \bigcirc)$, moderate $(\otimes \otimes \otimes \bigcirc)$, and high $(\otimes \otimes \otimes \otimes)$. Briefly, 'very low quality' evidence is derived from unsystematic clinical observations (case reports, case series) or very indirect evidence (e.g. surrogate endpoints); 'low quality' evidence is from observational studies or randomized controlled trials (RCT) with major limitations; 'moderate quality evidence' derives from RCTs with significant limitations or from rigorous observational studies; 'high quality evidence' are well-performed RCTs and, in some exceptional cases, strong evidence from unbiased observational studies (5).

In order to quantify the level of agreement among the panelists about the recommendations and suggestions, the RAND-UCLA appropriateness method has been applied (7). Briefly, for each recommendation or suggestion, the panelists have indicated a score ranging from 1 (maximum disagreement) to 9 (maximum agreement). Indications with median scores in the 1-3 range are classified as 'inappropriate', those in the 4-6 range as 'uncertain', and those in the 7-9 range as 'appropriate'. Recommendations

Table 1 Level of evidence (LOE) of the studies included for this statement.

\begin{tabular}{|c|c|}
\hline $\begin{array}{l}\text { Level of } \\
\text { evidence }\end{array}$ & References \\
\hline No LOE & $\begin{array}{l}1,2,3,4,5,6,7,8,9,11,12,13,14,15,19,20,22,23,25,35,36,37,38,41,51,56,60,61,64,66,67,69,71,78,79, \\
80,82,84,85,95,97,99,100,101,102,106,107,111,113,119,128,137,149,151,152,156,158,159,162,168,176, \\
177,179,181,187,192,197,198,200,202,205,211,213,214,215,226,227,228,229,235,236,242,243,244\end{array}$ \\
\hline$\otimes 000$ & $\begin{array}{l}26,31,32,33,39,40,44,45,50,52,53,54,55,62,68,70,74,75,76,77,81,83,86,87,88,89,90,91,92,110,115, \\
116,117,127,133,150,157,174,185,189,191,193,195,196,199,204,206,220,221,232,233,234,237,239\end{array}$ \\
\hline$\otimes \otimes \bigcirc \bigcirc$ & $\begin{array}{l}10,16,17,18,21,24,27,28,29,30,34,42,43,46,47,48,49,57,58,59,63,65,72,73,89,93,94,96,98,103,104, \\
112,114,118,120,121,122,123,124,126,129,130,131,132,140,141,145,146,153,154,160,166,167,169,170 \\
171,172,175,178,182,183,184,188,190,194,201,203,207,208,209,210,212,222,223,224,230,231,238,240\end{array}$ \\
\hline$\otimes \otimes \otimes \bigcirc$ & $105,109,125,135,136,138,139,142,143,144,147,148,155,163,165,173,180,216,217,218,219,225,241$ \\
\hline$\otimes \otimes \otimes \otimes$ & $108,134,161,164,186$ \\
\hline
\end{tabular}


and suggestions rated as inappropriate have obviously not been released. Furthermore, some measures of the dispersion of panel ratings, which are taken as an indicator of the level of agreement/disagreement with which the ratings were made, have been calculated. Finally, for each recommendation/suggestion, the following additional information has been reported:

- Appropriate: panel median (range 7-9), without disagreement.

- Uncertain: panel median (range 4-6) OR any median with disagreement.

\section{1.c. Epidemiology, morbidity, and mortality}

Prolactinomas are the most common pituitary adenoma, accounting for approximately $50 \%$ of all pituitary adenomas, with a prevalence of $\sim 50$ per 100000 population and an incidence of 3-5 new cases/100 000/year $(8,9)$. In autoptic series, a high prevalence of undiagnosed pituitary adenomas (almost all tiny tumors) has been detected (10.4\%) and prolactinomas represented $40 \%$ of them (10).

Based on tumor size, they are classified as microprolactinomas (microP, $<10 \mathrm{~mm}$ diameter) or macroprolactinomas ( $\mathrm{MP}, \geq 10 \mathrm{~mm}$ diameter). MicroPs are mainly observed in premenopausal women, whereas MPs are more common in men aged more than 50 years. Giant tumors $(>40 \mathrm{~mm})$ are rare $(1-5 \%$ of all prolactinomas). They are diagnosed mostly in men aged between 20 and 50 years (median 42 ) and occasionally in older men or postmenopausal women and even in the pediatric population, with a reported male-to-female ratio of $\sim 9: 1$ $(11,12)$.

In a few cases, other pituitary hormones are secreted in excess beyond prolactin (PRL) (mostly growth hormone $(\mathrm{GH})$ ).

PRL-producing pituitary carcinomas are rare and defined by the presence of cerebrospinal, meningeal, or systemic metastases (13).

In clinical series of patients aged more than 65 years, prolactinomas account for $4-8 \%$ of pituitary adenomas but the prevalence may be actually underestimated in elderly women and men due to reduced attention to symptoms of hypogonadism $(9,11)$.

Pituitary adenomas are rare in children and adolescents and account for 3-4\% of all intracranial tumors in this age group (14). The mean age at diagnosis was $16.1 \pm 2.5$ years (range: $4.5-20$ years). The incidence of prolactinomas in this age group is 0.1 per 1000000 population, and they are more frequently diagnosed in girls than in boys (up to
$80 \%$ of cases) (15). MPs are more prevalent than microPs in pediatric populations (58\% vs $42 \%$ ) (16). Prolactinomas are larger and more frequently invasive in boys than in girls as in the adult counterpart (16).

Prolactinomas can also belong to genetic syndromes (see below at 4.d), with a reportedly higher aggressive behavior.

Prolactinomas are not associated with increased prevalence of diabetes, cardiovascular diseases, and cancer, as showed in a population-based cohort followed for 26 years in Tayside, Scotland (PROLEARS study) (17). Premature mortality was reported in patients bearing MP but not microP. The authors hypothesized that hypopituitarismassociated hormonal deficiencies or their overtreatment might contribute to adverse health outcomes.

\section{Executive summary of recommendations $(\mathbf{R})$}

All the $\mathrm{R}$ have been released with agreement, according to RAND-UCLA criteria (7).

\section{2.a. Diagnosis (see sections 4 .a for $R \mathbf{1 - 1 1}$, $4 . b$ for $R$ 2, 4.c for $R$ 12-15, 4.d for $R$ 16)}

- R 1. We recommend measuring PRL levels in all patients with a clinical suspicion, namely oligo-amenorrhea in females, erectile dysfunction in males, galactorrhea or infertility in both sexes, and pathologic findings at MRI of the sellar region (level of agreement - LoA 9).

- $\mathbf{R}$ 2. We recommend a detailed medical and pharmacological history be taken. Physiological (pregnancy and breastfeeding), secondary, and iatrogenic causes of hyperprolactinemia should be ruled out (LoA 9).

- R 3. We recommend confirming the finding of randomly elevated PRL level with the insertion of an i.v. catheter and saline infusion for 15-20 min before blood sampling for PRL assay, unless PRL is clearly elevated (>80-100 ng/mL) (LoA 9).

- R4. We suggest that any clinician should be acquainted about the employed PRL assays (unit of measure, etc) (LoA 8).

- R 5. We recommend screening for macroprolactin in (1) asymptomatic patients, (2) patients with atypical clinical picture, (3) patients with conflicting PRL results in distinct assays, and (4) patients with lack of decline of serum PRL levels with DA, and we suggest this screening in patients with macroadenoma and PRL levels in the so-called gray area (100-200 ng/mL) (LoA 9). 
- R 6. We recommend that in cases of large pituitary adenomas (i.e. $>3 \mathrm{~cm}$ ) associated with normal or mildly elevated PRL levels, PRL levels should be measured after serial sample dilution to rule out hook effect (see text for details) (LoA 8).

- R 7. We suggest that the magnitude of PRL levels can be useful in determining the etiology of hyperprolactinemia in patients with pituitary tumors, namely that PRL levels $>200-250 \mathrm{ng} / \mathrm{mL}$ are almost always due to a macroprolactinoma (LoA 8).

- R 8. We suggest defining a clear starting level of PRL (i.e. don't settle for a vague indication of 'higher than, for example, $1000 \mathrm{ng} / \mathrm{mL}^{\prime}$ ) in patients with MP to make easier the follow-up on pharmacologic treatment (LoA 8).

- R 9. We recommend screening of hypopituitarism at diagnosis (LoA 9):

o In all patients with MP,

- In microP only if there is a clinical suspicion.

- R 10. We suggest evaluating insulin-like growth factor I (IGF-I ) levels in all PRL-secreting tumors at diagnosis (LoA 7.5).

- R 11. We recommend that in cases of possible medication-induced hyperprolactinemia, highfield MRI with Gd should be performed only if there is persistence of hyperprolactinemia following withdrawal or replacement (whenever possible) of offending medication or if the patient is clinically unable to withdraw the drug suspected of causing the hyperprolactinemia (LoA 9).

- R 12. We suggest a careful neuroradiological evaluation guided by clinical context to avoid false positive diagnoses (LoA 9).

- R 13. We recommend MRI control within 3-6 months for MP and suggest it within 1 year for microP after DA initiation. Earlier follow-up should be considered in case of non-responders or new symptoms (LoA 9).

- R 14. We suggest limiting the use of Gd during follow-up (especially in MPs) (LoA 8).

- R 15. We recommend that a genetic basis for prolactinoma should be suspected based on family history, early onset of the adenoma (i.e. before 20 years) and aggressive behavior (i.e. uncontrolled tumor growth despite appropriate treatment), and concomitant other endocrine diseases (LoA 8.5).

\section{2.b. Treatment}

\section{General aspects (see sections 5.a, 5.b, 5.c, 5.f)}

- R 16. We suggest discussion of the therapeutic strategy in a multidisciplinary tumor board, mostly in MP (this should be a strong recommendation, but it was downgraded due to the limitations of real world) (LoA 8).

- R 17. We recommend referral to an expert pituitary surgeon (defined according to skill and caseload as detailed in the text) whenever neurosurgery is considered (LoA 9).

- $\mathbf{R}$ 18. We recommend that transsphenoidal resection of the adenoma be presented as a viable option to any patient with a radically resectable adenoma (microP or enclosed MP), ideally during a joint evaluation with the endocrinologist and the neurosurgeon (LoA 9).

- R 19. We suggest transsphenoidal resection of the adenoma whenever treatment is required and the patient is unwilling to take a chronic pharmacologic treatment (LoA 9).

- $\mathbf{R}$ 20. We recommend treatment with DA, namely cabergoline (Cab), at the lowest effective dose capable to control PRL hypersecretion and tumor volume (LoA 9).

- $\mathbf{R}$ 21. We suggest bromocriptine $(\mathrm{Br})$ treatment in patients with intolerance to $\mathrm{Cab}$ who are not candidate for surgery, as well in the setting of Cab unavailability or low-resource countries (LoA 8).

- R 22. We recommend alerting patients who start Cab treatment and their caregivers about the possible development of impulse control disorders (ICD) and inquiring regularly for psychiatric symptoms during chronic treatment (LoA 8.5).

- R 23. We suggest periodic cardiac auscultation and ultrasonography in patients with a murmur or consuming more than $2 \mathrm{mg}$ per week of Cab, without overlooking extra-endocrine causes of valvular involvement (LoA 7).

\section{Microprolactinoma (see sections 5.b, 5.c)}

- R 24. We recommend that the aim of treatment is the reversal of clinical picture, mainly hypogonadism (LoA 9).

- R 25. We suggest that simple clinical observation can be appropriate if hypogonadism or galactorrhea are not an issue, as well as oral estroprogestinic contraceptives in women not seeking pregnancy (LoA 8.5).

- $\mathbf{R}$ 26. We recommend surgery in patients resistant/ intolerant to DA (LoA 9).

- $\quad \mathbf{R}$ 27. We recommend DA withdrawal in females after the menopause (LoA 7.5).

\section{Macroprolactinoma (see sections 5.b, 5.c, 5.d, 5.f)}

- R 28. We recommend first-line Cab treatment, no matter how large the tumor size or severe the neurological and ophthalmologic damage, under tight clinical and 
lab control to quickly improve neuro-ophthalmologic symptoms (LoA 9).

- $\mathbf{R}$ 29. We recommend resection of the adenoma by an expert pituitary surgeon in patients without quick improvement of severe neuro-ophthalmologic damage on DA (within 2 weeks), or resistant/intolerant to DA, or with escape from DA effects (LoA 9).

- $\mathbf{R}$ 30. We recommend careful and tight follow-up of patients with partial response to DA and their quick referral to an expert neurosurgeon whenever the efficacy of DA treatment fades (LoA 9).

- R 31. We suggest that in good DA-responders (after PRL normalization and tumor shrinkage), follow-up can be safely performed in most cases only with PRL assessment at yearly intervals. MRI can be safely performed every other year or longer and even avoided if PRL levels remain normal (LoA 8).

- $\quad$ R 32. We recommend urgent evaluation by an ENT or a neurosurgeon in case of nasal cerebrospinal fluid (CSF) leakage (LoA 9).

- $\quad$ R 33. We suggest DA withdrawal in MP only in patients showing complete disappearance of tumor mass (or at least a 50\% decrease in tumor size) and persistence of low-normal PRL levels after progressive downtitration of DA during chronic treatment, with a careful quarterly follow-up of PRL levels and gonadal status (LoA 7.5).

- $\quad \mathbf{R}$ 34. We recommend against DA withdrawal in MP patients on chronic DA treatment with persisting tumoral tissue and pathologic PRL levels (LoA 9).

- $\quad \mathbf{R}$ 35. We recommend irradiation in patients with MP that cannot be controlled by DA and surgery (LoA 9).

- $\mathbf{R}$ 36. We suggest that radiotherapy, regardless of the chosen technique, should be discussed within a multidisciplinary pituitary team (LoA 9).

- R 37. We suggest that, when available and technically feasible, radiosurgery should be used over fractionated radiotherapy, unless the tumor is too close to the optic pathways or tends to diffusely infiltrate the surrounding anatomical structures (LoA 9).

- $\quad \mathbf{R}$ 38. We recommend prolonged yearly follow-up to evaluate the efficacy and safety of radiotherapy (LoA 9).

\section{2.c. Special cases}

\section{Children (see section 5.e.i)}

- R 39. We suggest DA treatment in children with prolactinoma, to preserve normal pituitary function, reserving neurosurgery for those resistant or intolerant to this treatment (LoA 9).
Gonadal replacement, contraception, fertility, pregnancy, and menopause (see sections 5.b.iii, 5.e.ii, 5.e.iii, 5.e.iv)

- $\mathbf{R}$ 40. We recommend early testosterone replacement treatment (TRT) in males with persistent hypogonadism, namely within 3-6 months after the start of DA, provided that PRL is progressively decreasing (LoA 9).

- $\mathbf{R}$ 41. We recommend a case-by-case evaluation of gonadal replacement therapy in hypogonadal women with MP (LoA 9).

- R 42. We suggest that hormone replacement treatment in hypogonadal female patients be continued at least until the age of physiologic menopause (LoA 9).

- $\mathbf{R}$ 43. We suggest estroprogestinic administration as a safe option in DA-responder women with microP or well-responsive MP requiring contraception (LoA 8.5).

- $\mathbf{R}$ 44. We suggest restoration of fertility with gonadotropins, whenever required (LoA 9).

- $\mathbf{R}$ 45. We recommend planning pregnancy (LoA 9).

- $\mathbf{R}$ 46. We recommend full information of the pregnant patient and easy access to an endocrinologic consultation (LoA 9).

- $\mathbf{R}$ 47. We recommend DA treatment (preferably Cab for better tolerability) while seeking pregnancy and its discontinuation at confirmation of pregnancy (LoA 9).

- $\mathbf{R}$ 48. We recommend against checking PRL levels during pregnancy (LoA 9).

- $\mathbf{R}$ 49. We recommend only clinical follow-up throughout gestation in patients with microP or a small intrasellar remnant of MP (LoA 9).

- R 50. We recommend clinical and pituitary function evaluation and neuro-ophthalmologic evaluation in patients with MP during pregnancy in each trimester (LoA 9).

- R 51. We recommend against pituitary MRI scan during uneventful pregnancy and in the early postpartum period (LoA 9).

- $\mathbf{R}$ 52. We recommend neuro-ophthalmologic evaluation, MRI without Gd, and pituitary function evaluation in patients who develop mass effect symptoms during pregnancy (LoA 9).

- $\mathbf{R}$ 53. We recommend reinstitution of DA during pregnancy (preferably Cab) in symptomatic patients with $\mathrm{MP}$, to obtain a rapid remission of symptoms and to be maintained even after delivery (LoA 9).

- R 54. We suggest vaginal delivery in microP (unless otherwise indicated by the obstetrician) and a case-bycase evaluation in MP (LoA 9). 
- R 55. We recommend that women with prolactinomas be allowed to breastfeed, provided that pregnancy was uneventful, postponing the possible restart of DA (LoA 9).

- R 56. We suggest adopting nonhormonal contraceptive measures after delivery or after the cessation of breastfeeding in order to evaluate PRL levels at 3-6 months in all women and subsequent MRI in MP (LoA 8).

- R 57. We recommend reinstitution of DA in women with relapsing symptomatic hyperprolactinemia after delivery (LoA 9).

- $\mathbf{R}$ 58. We recommend DA discontinuation after menopause in microP, with yearly monitoring of PRL if elevated and MRI in case of progressive PRL increase (LoA 8).

- R 59. We recommend carrying on DA treatment in MP after menopause at the lowest dose capable to control tumor growth and follow-up according to clinical status (LoA 9).

\section{Miscellany (see sections 5.e.v, 5.e.vi, 5.e.vii)}

- R 60. We suggest that the treatment of prolactinoma does not change in the presence of breast cancer (LoA 9).

- R 61. We suggest evaluating PRL levels before starting treatment with neuroleptics (LoA 8).

- R 62. We recommend a tight collaboration between the endocrinologist and the psychiatrist for the management of patients with psychiatric disorders and hyperprolactinemia (LoA 9).

- R 63. We suggest that the patient with prolactinoma on antipsychotic treatment can be managed with DA with an individual evaluation of efficacy and safety (LoA 8).

- R 64. We suggest the evaluation of bone health to decide the additional start of bone-active treatment (LoA 9).

\section{DA resistance and aggressive disease (see sections}

\section{5.e.viii, 5.f)}

- R 65. We recommend tight follow-up in all patients with MP, mostly in males due to their elevated risk of unfavorable course (LoA 9).

- R 66. We recommend that an expert pituitary team adopt a quick multimodal approach (repeated surgery+radiotherapy+DA) in case of resistance or escape to DA or uncontrolled tumor growth (LoA 9).

- $\mathbf{R}$ 67. We recommend therapy with temozolomide in patients with MP resistant to DA who had unsuccessful surgical and/or radiation treatments or those with evidence of metastases (LoA 9).
- R 68. We suggest temozolomide withdrawal after the third cycle of treatment in patients with progression of disease (LoA 8.5).

- R 69. We suggest that patients with aggressive disease and no response to temozolomide can be treated with experimental approaches (LoA 8).

\section{Clinical issues}

\section{3.a. Patients' complaints that might lead to the evaluation for hyperprolactinemia}

The patient may seek medical evaluation complaining of different troubles, according to gender and age.

Women in reproductive age complain of endocrine symptoms such as oligo-amenorrhea or short luteal phase (with more frequent cycles) $(85-90 \%)(1,8,18)$, decreased libido (19), anovulatory infertility (20), and spontaneous or provoked galactorrhea. Galactorrhea occurs in nearly $90 \%$ of premenopausal women (21). Occasionally galactorrhea occurs in non-lactating women with regular menses and normal PRL values ('nonpuerperal idiopathic galactorrhea') (22).

Postmenopausal women usually present with symptoms due to mass effect related to a large tumor (see below), whereas galactorrhea is less frequent as the mammary glands are not primed with estrogen and progesterone anymore (21).

Approximately half of males typically present with symptoms caused by the tumor mass (see below) and the other half with symptoms of hypogonadism (8), most frequently loss of libido, erectile dysfunction, diminished ejaculate volume, infertility with impaired spermatogenesis, less frequently gynecomastia, and galactorrhea (23). All these effects are mostly caused through impairment of gonadotropin secretion and hypotestosteronemia (24). Due to hypogonadism, men may also complain of decreased energy and muscle mass, and anemia (11).

Clinical presentation varies by age and sex also in children and adolescents $(16,25)$. During the prepubertal period, headache, growth failure, and visual field defects are the most frequent signs, while during puberty, galactorrhea, hypogonadism, or pubertal arrest are additional characteristics.

Weight gain can be a presenting symptom for patients with newly diagnosed prolactinomas (26), even though its mechanism is still to be elucidated (27), and this should be a consideration in the investigative and treatment algorithm of prolactinomas. Overweight or obesity at diagnosis seems 
highly prevalent, both in pediatric (16) and adult age (28, $29)$. Weight loss is frequently recorded in prolactinoma male patients who normalized their PRL levels (29).

Patients at any age may seek medical attention due to mass effect symptoms occurring in about half of patients with MPs (8). The most frequent is visual impairment, due to upward adenoma extension/invasion with chiasmal compression, mainly expressing as field defects, such as unilateral or bilateral supero-temporal quadrantopia or temporal hemianopia. Headache is frequent in MP (but may occasionally occur even in microP) $(30,31,32,33)$. Hypopituitarism could be due to direct compression of the adenoma on the normal pituitary tissue or to stalk compression with hypothalamic disconnection, or even to apoplexy (8). In case of apoplexy, severe headache, visual impairment, and ophthalmoplegia may be the presenting symptoms.

Other symptoms depend on the site of adenoma extension/invasion. If it is upwards, it may occasionally cause hydrocephalus. In case of caudal extension, skull base structures destruction and occasional spontaneous CSF leakage may very rarely occur (34). Extension of the adenoma in other directions may cause other cranial nerve palsies (cranial nerves VI, IV, III), hearing impairments, hemiparesis, temporal epilepsy, or dementia due to frontal lobe extension (35).

\section{3.b. Sequela of hyperprolactinemia}

Osteoporosis

Hyperprolactinemia per se or through hypogonadism induces an increased bone turnover, with a predominance of bone resorption and, consequently, an increased occurrence of osteopenia and osteoporosis (11, 36, 37, 38). Suppressed levels of osteocalcin (OC), high collagen type I crosslinked N-telopeptide (NTX), and increased receptor activator of nuclear factor-kB ligand (RANKL)/ osteoprotegerin ratio have been reported in patients with prolactinoma $(39,40)$. Both in females and in males, trabecular bone in the spine and in the hip is more affected than cortical bone in the distal radium; in fact, spinal bone mineral content is generally reduced from 20 to $30 \%$ and forearm bone mineral content from 2.5 to $10 \%$ (41). The difference in bone loss according to sites is likely due to a more rapid turnover of trabecular bone.

Tumoral hyperprolactinemia per se or through hypopituitarism may impair the attainment of peak bone mass in young patients (42) and bone mineral density (BMD) may be reduced in childhood-onset prolactinoma patients (43).
Hypogonadotropic hypogonadism is considered the main mechanism responsible for bone changes induced by hyperprolactinemia $(44,45,46,47)$. Some recent clinical studies have suggested that hyperprolactinemia can also act directly on bone. A higher prevalence of vertebral fractures has been shown in women and men with prolactinoma independently of gonadal status (48, 49). In a series of 78 women affected by PRL-secreting pituitary adenomas, the prevalence of vertebral fracture appeared to be related to the length and severity of hyperprolactinemia, to BMD T-score value, and to the treatment. Also, a $60 \%$ increase in the risk of clinical fractures in prolactinoma before the diagnosis of disease as compared to controls has been reported (50). On the other hand, the PROLEARS study showed an increased risk of fractures but only in the drug-induced hyperprolactinemia subgroup (17).

\section{Quality of life (QoL)}

Few data are available on QoL in patients affected by hyperprolactinemia and prolactinomas $(51,52,53,54,55)$. Most of them are based on female population and on the SF36 questionnaire (a self-administered questionnaire that does not include sexuality and hypogonadism symptoms). Anxiety, depression, fatigue, and decreased well-being are the most frequently reported symptoms. Some studies have also reported sleeping difficulties. Despite usual QoL improvement after treatment, impairment of physical and emotional aspects as well as social isolation may persist. Data are discordant about the correlation between PRL levels and well-being awareness.

\section{Diagnostic issues}

The diagnosis of hyperprolactinemia is established by measuring basal PRL levels. Hyperprolactinemia is the hallmark not only of PRL-secreting tumors but also of nonsecreting neoplasms of the hypothalamo-pituitary region and of a variety of disorders that must be excluded before prolactinoma is diagnosed.

The magnitude of PRL levels can be useful in determining the etiology of hyperprolactinemia. PRL levels generally correlate with prolactinoma size, namely up to $150 \mathrm{ng} / \mathrm{mL}$ in most patients with microP and higher than $200-250 \mathrm{ng} / \mathrm{mL}$ in patients with MP. An increase of PRL levels can be caused by non-secreting pituitary lesions (the so-called pseudoprolactinomas), such as nonsecreting adenomas, as well as other tumoral, infectious, and inflammatory processes involving the hypothalamus, 
the perisellar region, the pituitary stalk, and the pituitary itself or a primary empty sella. This 'stalk effect' is due to the disconnection between the hypothalamus and the pituitary gland, with the consequent impairment of the inhibitory dopaminergic pathways and increase of PRL levels. In pituitary macroadenomas, PRL levels below 100 $\mathrm{ng} / \mathrm{mL}$ can be attributed to this phenomenon, whereas PRL concentrations between 100 and $200 \mathrm{ng} / \mathrm{mL}$ represent a 'gray zone' that should prompt differential diagnosis between prolactinoma and pseudoprolactinoma $(56,57$, $58,59)$.

\section{4.a. The conundrum of PRL assays and laboratory workup (R 1-10)}

Pre-analytical requirements

PRL secretion is pulsatile, and levels are physiologically higher during sleep and in the early morning (60).

Emotional stress, venipuncture, exercise, walking, and a protein-rich diet all stimulate PRL secretion (61). Thus, specimens collected after an overnight fast, at least $2 \mathrm{~h}$ after awakening when the patient is resting, provide the most reliable PRL assessment (62). The insertion of an i.v. catheter 15-20 min before sampling for PRL assay in the diagnostic phase is a simple and practical tool in cases of mild hyperprolactinemia (63).

\section{Analytical specifications}

PRL assays typically involve noncompetitive, heterogeneous 'sandwich' techniques that use two antibodies that recognize different epitopes on the PRL polypeptide. PRL methods should be calibrated against reference materials with known international unit potency, such as the WHO first IRP 75/504, the second international standard (IS) $83 / 562$, or the third IS $84 / 500$.

Heterogeneity in the molecular size of PRL has been described with three major variants in the majority of sera from normal and hyperprolactinemic individuals (64). The monomeric or little PRL represents $80-95 \%$ of the total PRL in cases with normoprolactinemia and true hyperprolactinemia. The biological and immunological activity of PRL may be almost exclusively attributed to this form. Other forms of PRL with lower biological activity include the dimeric (big PRL) and the polymeric isoform or macroprolactin (big-big PRL), that account for less than 10 and $1 \%$, respectively, of the total PRL levels in normal sera.

Macroprolactinemia represents a state of hyperprolactinemia characterized by the predominance of big-big PRL (at least 60\% of circulating PRL), and it should be suspected in asymptomatic individuals or those without the typical hyperprolactinemia-related symptoms. Although the nature of macroprolactin is heterogenous, it is mainly recognized as an antigenantibody complex, consisting primarily of monomeric PRL and immunoglobulin G isotype. The high molecular size of macroprolactin prevents its access to PRL receptors at the level of target organs, with the loss of hyperprolactinemiarelated symptoms. The prevalence of macroprolactinemia ranges from 8 to $42 \%$ among hyperprolactinemic individuals (reviewed in (56)). Such patients should be reassured that neither pituitary imaging investigations nor DA treatments or follow-up are necessary.

Misdiagnosis and mismanagement were a frequent occurrence before the introduction of macroprolactin screening by the use of appropriate laboratory techniques (65), to determine the relative amounts of macroprolactin and monomeric PRL in blood samples of hyperprolactinemic patients, at least if clinical picture is not straightforward. The gold standard for the diagnosis of macroprolactinemia is gel filtration chromatography, but because this method is time-consuming and expensive, polyethylene glycol serum precipitation has been widely used as a screening method. A chemiluminescent immunoassay for monomeric PRL is now available, with lower interference with big-big PRL. Recoveries of PRL levels $<40 \%$ are indicative of predominance of macroprolactin, whereas recoveries $>60 \%$ point to the diagnosis of monomeric hyperprolactinemia (60). Anyway, the absolute value of monomeric PRL (either normal or elevated) should beconsidered for the diagnosis after removal of the polymeric forms (60). The assessment of macroprolactinemia has been recommended as financially justified since it reduces use of imaging and unnecessary and ineffective DA treatment in such patients (66). Macroprolactinemia associated with prolactinoma and typical hyperprolactinemic symptoms has been reported (67).

Artificially low PRL levels may result from the so-called hook effect. It is an assay artifact caused by an extremely high level of PRL, which saturates the detecting antibody used in the PRL sandwich assay, thus resulting in a falsely low reported value $(60,68)$. The hook effect may be unmasked by repeating PRL measurement after a serum sample dilution. This step will result in a dramatic rise in PRL levels if the patient has a MP, remaining unchanged in cases of non-functioning adenoma $(60,68)$. Hook effect is a very rare occurrence nowadays with modern assays and might be considered in all cases of large $(\geq 3 \mathrm{~cm})$ pituitary adenomas associated with normal or mildly elevated PRL levels $(\leq 250 \mathrm{ng} / \mathrm{mL})$. 
Sample dilution should be considered when the laboratory report does not indicate a distinct PRL value, but only "level greater than, for example, 200 or 470 $\mathrm{ng} / \mathrm{mL}$ (the levels corresponding to the upper value of the calibration curve for the most widely employed immunoassay platforms)", in order to set a clear starting level for follow-up on pharmacologic treatment.

Further assay interference should be considered and ruled out whenever there is discrepancy between measured PRL levels and clinical picture or MRI. Biotin is contained in many over-the-counter integrators and may cause interference in many assays that are based on biotinylated antibodies (69). PRL measurement should be repeated after the withdrawal of such interfering substances for a few days. Heterophil antibodies are another rare possible cause of misdiagnosis that could be overcome with appropriate treatment of the sample (70).

\section{Endocrine workup in patients with prolactinoma}

As in all pituitary macroadenomas, screening of hypopituitarism is warranted in MP. This should include in all patients the determination of morning serum cortisol and FT4, in order to start timely an appropriate replacement therapy (71). If not already available, testosterone levels in males and estradiol levels in females should be evaluated. The evaluation of gonadotropins can complete hormonal workup.

In case of microP, even though the occurrence of hypopituitarism was occasionally reported (72), an endocrine workup should be performed only if there is a clinical suspicion.

Regardless of tumor size, IGF-I evaluation should be performed at diagnosis in all patients with prolactinomas to rule out a mixed hypersecretion of GH and PRL (73). The search for other associated pituitary hormone hypersecretions should be driven by the clinical context.

\section{4.b. The hunt for non-tumoral causes of hyperprolactinemia $(\mathrm{R} 2,11)$}

In many patients, increased serum PRL concentrations are due to physiological causes as pregnancy or stress, drug administration, or are secondary to diseases other than prolactinomas. PRL levels generally are only mildly elevated in these settings.

\section{Secondary non-endocrine diseases}

In liver cirrhosis, PRL is increased due to increased estrogen milieu and decrease of dopaminergic tone. Concentrations are generally lower than $100 \mathrm{ng} / \mathrm{mL}$ and are correlated to Child-Pugh score (74).

In chronic renal disease, decreased renal clearance and imbalance of neurotransmitters increase serum PRL in the range of 30-100 ng/mL (75). PRL levels can be even higher in the patient with chronic kidney disease consuming medications that interfere with dopaminergic inhibition of PRL. Only kidney transplantation restores normal PRL levels in patients with renal failure.

Increased concentrations of PRL have rarely been reported in the so-called 'neurogenic' hyperprolactinemias, such as breast manipulation (mammoplasty, piercing), chest wall disease (as Herpes Zoster), or neurinoma of intercostal nerves (11).

Another rare occurrence is severe PRL excess in association with internal carotid artery aneurism (76).

\section{Endocrine diseases different from prolactinomas}

The stalk effect due to the disconnection between the hypothalamus and the pituitary gland has been already described (see above).

The increase of PRL in primary hypothyroidism is wellknown and correlates with the severity of hypothyroidism. Hyperplasia of thyrotroph and lactotroph cells due to TRH stimulation may induce a radiologically evident increase of pituitary size and a false diagnosis of pituitary adenoma in younger patients, in whom thyroxine replacement therapy normalizes pituitary size (77).

PRL levels are increased in 11-16\% of patients affected by PCOS and 50-70\% of these actually have a microP (8). The rise of PRL is generally mild but may contribute to hyperandrogenism (11).

\section{Medication effects}

Many drugs can increase serum PRL levels through different mechanisms. The most common and important action is through dopamine type 2 receptor (D2R) antagonism, others are inhibition of dopamine synthesis, dopamine depletion, and effects on serotonin metabolism or action (Table 2).

Antipsychotic and antidepressant drugs are by far the most frequent (78). The occurrence and magnitude of PRL increase are dependent on the specific drug, but there is an individual susceptibility, due to age, sex, and D2R polymorphisms (79). The levels of PRL are generally lower than $100 \mathrm{ng} / \mathrm{mL}$, but a few patients have higher values.

First-generation or typical antipsychotics (phenothiazines, thioxanthenes, butyrophenones) are 
characterized by a high potential to raise PRL levels. The second-generation or atypical neuroleptic drugs generally cause less frequent and marked increase of PRL, except for amisulpiride and risperidone. Furthermore, some secondgeneration antipsychotic drugs, such as aripiprazole, quetiapine, clozapine, ziprasidone, and olanzapine, have really low probability to increase PRL, and aripripazole can even lower PRL levels (80). With anti-depressant drugs the increase in PRL is generally mild, except for the selective serotonin reuptake inhibitors.

The antiemetics and prokinetics drugs domperidone, metoclopramide, and L-sulpiride determine a huge increase of PRL levels because of the antagonism at the D2R. This effect should not be overlooked as they are overthe-counter drugs.

Estrogens cause PRL increase (81), but this is less relevant with current dosages employed as contraceptives or replacement treatments. Most studies with estrogen replacement therapy (ERT) for menopause have shown either no effect or minimal effect on PRL levels with varying doses of estrogens up to $1.25 \mathrm{mg}$ of conjugated estrogens or $50 \mu \mathrm{g}$ of estradiol daily (60). About $20 \%$ of women taking combined oral contraceptives develop mild hyperprolactinemia (60), but it should be kept in mind the possibility of a concomitant organic cause for PRL elevation in cases of moderate-severe hyperprolactinemia (>50 ng/mL).

Whenever an iatrogenic cause of hyperprolactinemia is suspected, PRL measurement should be repeated after discontinuing the culprit medication for 3-4 days. If this is not feasible or safe (as in most patients on antipsychotic drug therapy), MRI should be performed to rule out a sellar mass (60).

\section{Idiopathic hyperprolactinemia}

In some patients with increased serum PRL levels, no specific cause is identified. Physiological conditions, endocrine and non-endocrine diseases, and drugs should be excluded. Macroprolactin should be excluded as well (see above at 4.a.) and pituitary MRI should be normal. The risk of subsequent development of a microP is very low (82).

Very few cases are familial and due to mutation of the PRL receptor (83).

\section{4.c. Imaging of PRL-producing lesions when and how (R 11-14)}

\section{Technical specifications}

MRI is the gold standard for the radiological diagnosis of prolactinoma. The basic evaluation of MRI comprises T1-weighted images (WI), T2-WI, and Gd contrastenhanced T1-WI on coronal and sagittal planes. In some cases, when microP is not evident in pre-contrast imaging, dynamic T1 sequences with Gd are indicated (84). Although sensitivity for identifying microadenomas on 3-T MRI is reportedly better than on 1.5-T MRI in Cushing disease (85), no data support the same benefit in microPs. Thereby, there is no absolute indication to study patients with hyperprolactinemia with 3-T MRI. Additional sequences, such as susceptibility weighted images, particularly useful to assess blood and calcifications, also tagged as 'T star ( $\left.\mathrm{T}^{*}\right)$ ', may be useful in specific situations.

Only those patients with absolute contraindications to MRI will undergo CT scan. CT scan will demonstrate prolactinomas just like MRI but its accuracy in case of microadenomas is definitely lower. CT scan is usually performed, after MRI, before transsphenoidal pituitary surgery (TSS) to assess the anatomy of the sinuses.

\section{Prolactinomas on MRI}

Pituitary adenomas are usually mildly hypointense or isointense on T1-WI and have variable intensity on T2-WI (86). In one study, $80 \%$ of prolactinomas were reported to be hyperintense on T2-weighted MRI sequences when compared to the normal gray matter (87). Small cysts and hemorrhagic foci are common. Fluid-fluid levels can be present. T2 sequences can help recognize pituitary hemorrhage as well; this will usually appear

Table 2 latrogenic causes of hyperprolactinemia.

Antipsychotic drugs

Antidepressant drugs

Cardiovascular drugs

Gastrointestinal drugs

Miscellaneous
First-generation or typical antipsychotics: phenothiazines, thioxanthenes, butyrophenones Second-generation atypical neuroleptic drugs: amisulpiride, risperidone

Tricyclic: imipramine, amitriptyline

Selective serotonin reuptake inhibitors

Reserpine, verapamil, $\alpha$-methyl-DOPA

Metoclopramide, domperidone, L-sulpiride, cimetidine, ranitidine

Opioids, morphine, cocaine, marijuana

Anesthetics

Estrogens 
hypointense in $\mathrm{T} 2$ both in acute and chronic stages, while cystic components will be hyperintense on T2 (88). Their response to therapy is similar to non-cystic ones $(87,89)$. Signal hyperintensity along the optic pathways on T2/FLAIR, due to edema, occurs in 15-20\% of cases in which macroadenomas compress the optic chiasm. Most macroadenomas enhance strongly but heterogeneously on T1 post Gd. Subtle dural thickening (so-called dural 'tail'), more typical for meningiomas, is present in $5-10 \%$ of cases. Many microadenomas appear slightly hypointense on T1 with Gd, others may enhance strongly and become isointense with the enhancing pituitary gland, being virtually invisible. Most microPs enhance more slowly than the normal pituitary gland. Between 10 and 30\% of microPs are seen only on dynamic T1 post Gd imaging. If $\mathrm{Gd}$ is essential in the diagnosis of many microadenomas visible only after its injection, in macroadenomas it is able to better highlight features such as cavernous sinus invasion and position of residual normal pituitary gland.

One of the main problems when imaging a patient with suspect microP, especially with low hormone levels, is false-positive MRIs. False-positive MRIs can be related to the pathological interpretation of an anatomical variant or a technical artifact. These false positives are particularly dangerous, because they transform a normal subject into a patient who will undergo unnecessary follow-up and therapy. For this reason, it is essential that the MRI of the pituitary is interpreted by neuroradiologists, with an MRI of at least $1.5 \mathrm{~T}$, and following a rigorous methodology that includes the previously defined technique.

In case of microadenomas, the main differential diagnoses are clinically non-functioning microadenoma, Rathke's cleft cyst, or pars intermedia cyst. Main differential diagnoses of macroadenomas are pituitary hyperplasia, meningiomas, metastasis, craniopharyngioma, carcinoma, aneurysm, hypophysitis, and chordomas (90). Most of these pathologies can be easily differentiated from prolactinomas based on clinical symptoms, imaging features, and above all determination of PRL.

Pituitary adenoma invasion of local structures as assessed by MRI correlates with postoperative outcomes following surgical resection $(91,92,93)$. The Knosp grade, used to evaluate adenomas extension into the cavernous sinus on preoperative MRI, has been shown to be predictive of intraoperative tumor invasion, total resection, and postoperative hormonal remission.

Pituitary hemorrhage is significantly higher in MP (20\%) compared to microP (3\%), regardless of DA therapy. It is most common in females. In most cases, it does not cause symptoms; its complete resolution takes several months (mean 26) (94). Subclinical hemorrhage is much more frequent than pituitary apoplexy. Pituitary apoplexy may be the first symptom of a previously undiagnosed pituitary adenoma and is often misdiagnosed until MRI is performed.

\section{Follow-up imaging}

There is no clear consensus on a precise timing of follow-up MRIs for prolactinoma patients. The Endocrine Society (ES) clinical practice guidelines suggest repeating MRI routinely within 1 year for microP and within 1-3 months for MP after DA initiation, according to clinical context (1). At variance, in MP in case of PRL levels rising despite treatment or new visual disturbances, headaches, or evidence of a new hormonal dysfunction, prompt follow-up is suggested (1).

Although there is a clear correlation between size of adenoma and PRL levels $(57,58,59)$ before and after treatment, there are cases of discordance between tumor changes and PRL levels during therapy (95). In most of these rare cases, enlargement of MP during DA therapy with stable/reduced PRL levels is mostly related to pituitary hemorrhage (96). The timing of further MRI follow-up after the first performed at 1-3 months should be based on the individual clinical context, including the changes of neuro-ophthalmologic and endocrinological picture, pre-treatment adenoma size, signs of invasiveness, prior surgery, rate of PRL decline and tumor shrinkage on DA treatment, sex, estrogen state, as well as adherence to the medication (97). During chronic DA treatment, it is extremely important to review the entire series of available MRIs because subtle changes may not be observed when a comparison is limited to just two consecutive studies.

Enlargement of microP while on DA therapy was reported to be extremely rare (96). This observation has led some experts to recommend not performing follow-up MRI at least for microPs (98) unless PRL rises significantly (e.g. $>250 \mathrm{ng} / \mathrm{mL}$ ) or if severe headache, impairment of visual fields or visual acuity, or cranial nerve palsies develop $(99,100)$.

Because of the well-known deposition of most Gd chelates in many tissues (101) and the debate regarding the long-term effects of Gd exposition, it is suggested avoiding Gd-enhanced MRIs in the prolonged follow-up of MP.

\section{4.d. When to suspect and how to screen for genetic diseases ( $R$ 15)}

Most prolactinomas are sporadic as the other types of pituitary adenomas. Nevertheless, $1.5-3 \%$ of cases have a familial basis. 
All patients with prolactinoma need a careful family and personal medical history considering the suspect of a hereditary form. Early onset of the adenoma and aggressive behavior are additional elements to suspect a genetic form.

Multiple endocrine neoplasia (MEN) type 1 (MEN-1) is an autosomal dominant syndrome with high penetrance in which prolactinoma is the most frequent pituitary adenoma, present in $40 \%$ of patients (though pituitary adenomas in MEN-1 represent less than 3\% of all pituitary adenomas). Serum calcium should be measured to rule out primary hyperparathyroidism, the most common manifestation of MEN-1. Screening for pituitary tumors should be started at 9 years of age in carriers of the menin mutation (102). Prolactinomas in MEN-1 were traditionally considered more aggressive than sporadic ones, but recent studies based on early screening did not confirm such difference (103).

Familial isolated pituitary adenoma is characterized by the presence of only pituitary adenomas in affected members. Aryl hydrocarbon receptor interacting protein (AIP) is the most frequently involved gene. Transmission is autosomal dominant with relatively low penetrance. Prolactinomas along with somatotropinomas are the most frequent type of adenomas and show an aggressive behavior (104).

In Carney complex and in X-linked acrogigantism (X-LAG) syndrome, PRL is frequently increased but the clinical characteristics are those of somatotropinomas due to GH excess.

No prolactinoma has been reported in MEN-4.

\section{Therapeutic issues}

\section{5.a. Aims of treatment}

The ideal treatment for prolactinomas depends on its etiology:

- In microP, it aims for restoration of eugonadism and fertility and the resolution of galactorrhea.

- In MP, the aims are tumor shrinkage with disappearance of neurological and ophthalmologic symptoms, normalization of hyperprolactinemia with the consequent restoration of eugonadism and fertility, and the resolution of galactorrhea.

\section{5.b. Pharmacologic treatments}

\section{5.b.i. Dopaminergic drugs (R 20-23, 27-31, 33-34)}

Medical therapy with DA represents the first-line treatment in the management of almost all patients with prolactinomas, including microadenomas, macroadenomas, and giant adenomas (1).

DA normalizes serum PRL levels in almost $90 \%$ of patients with idiopathic hyperprolactinemia or microP and in $75-80 \%$ of patients with macroadenomas (105). Tumor shrinkage has been observed in more than $90 \%$ of treatment naïve MP patients (57).

Both hormonal and tumoral effects are mediated by the binding of DA to D2R on the membrane of adenoma cells, leading to reduction in synthesis and secretion of PRL and shrinkage of adenoma cells up to apoptosis (106).

Available DA are Cab, Br, quinagolide, pergolide, and metergoline. Pergolide and quinagolide are not available in Italy, metergoline is used only rarely.

$\mathrm{Cab}$ is the first choice of DA due to its efficacy, longacting effect (half-life ranging 63-109 h), and relatively uncommon adverse events (107). Cab was shown to be superior to the first used DA Br, due to its greater efficacy in decreasing and normalizing PRL levels, reducing tumor size, and its better tolerability (108). The bioavailability of $\mathrm{Cab}$ is not influenced by food intake (107). In general, Cab is started at $0.25-0.5 \mathrm{mg}$ weekly and given once or twice a week after dinner or at bedtime. According to clinical picture, the dose is uptitrated if needed at 1-3-month intervals in microP, at weekly intervals in MP with visual impairment (109).

Some patients are still treated with $\mathrm{Br}$ in specific situations, such as patients well controlled on Br for many years, or those that do not tolerate $\mathrm{Cab}$, or anecdotal cases of resistance to $\mathrm{Cab}$ (110). $\mathrm{Br}$ is conventionally given in two or three daily doses; however, a single evening dose has been shown to be equally effective. To prevent adverse effects, it is advisable to start treatment with a low dose during the evening meal or at bedtime $(1.25 \mathrm{mg})$ and gradually increase the dose by $1.25 \mathrm{mg}$ every $2-7$ days (111); doses greater than $30 \mathrm{mg}$ rarely have been used.

Microadenomas The aim of the treatment is to revert the effects of hyperprolactinemia, that is, spontaneous galactorrhea, and to restore gonadal function, that is, ovulatory menses in females, normal testosterone levels and sexual potency in males, and libido in both sexes. Treatment should be offered also to regularly cycling females with pathological hyperprolactinemia and anovulatory menses desiring pregnancy, and males with pathological hyperprolactinemia and normal testosterone levels complaining erectile dysfunction. Tumor shrinkage is not an issue in this setting because significant or persistent growth is uncommon according to studies of natural his- 
tory of untreated microPs (112), even in the presence of local tumor invasion. Amenorrheic premenopausal women not desiring pregnancy may be treated only with oral contraceptives, without DA, provided that patients do not complain of symptoms suggestive of tumor size increase and/or galactorrhea, PRL levels do not substantially increase, and evidence of tumor enlargement is not observed while on this treatment (1).

In females, Cab should be administered at the lowest dose capable of restoring regular menses and suppressing galactorrhea. The clinical response occurs within 12 weeks in about $80-90 \%$ of patients. In the steady state, this target is usually maintained with $0.25 \mathrm{mg}$ twice a week or 0.5 mg once a week, according to tolerability or the patient's preference. Female patients should be informed that treatment can early restore ovulation. Contraception may be thus required if needed. In a review of 14 prospective studies in patients with hyperprolactinemic disorders, Cab was successful in normalizing PRL levels in 73-96\% (113). In addition, tumor shrinkage was reportedly observed in $50-100 \%$ of Cab-treated microP (113).

A wide variability exists in clinical response. Some females require full PRL normalization to resume ovulatory menses, whereas in others, clinical response may be observed despite still pathological PRL values. At variance, in males usually testosterone levels are normalized and sexual activity is fully regained only after the normalization of PRL levels that may require several weeks. Accordingly, Cab dose should be individually tailored, with uptitration to $1.0-2.0 \mathrm{mg} /$ week (or even more) or downtitration to the lowest effective dose.

DA should be discontinued in pregnancy (see below at 5.e.iii) and might be withheld in some particular cases, such as perimenopausal women, asymptomatic postmenopausal women, or asymptomatic men without hypogonadism in whom simple observation with periodic monitoring of PRL could be considered (114, 115, 116, 117).

Macroprolactinomas The aims of the treatment in these patients are the quick relief of neuro-ophthalmologic symptoms when present, the normalization of PRL levels, and tumor shrinkage. The first is a compulsory aim in all patients, whereas the second and third ones should be pursued but are not always obtained.

$\mathrm{Cab}$ is always the first-line option in MP, even in patients bearing huge adenomas and/or severe neurologic symptoms or visual defects. In these patients, the thorough uptitration of Cab can quickly improve neurological and visual symptoms and lower abruptly PRL levels.
Cab is effective at doses ranging from 0.5 to $2 \mathrm{mg}$ weekly in most MP (118). A marked decline in PRL levels and tumor shrinkage may be obtained with very low Cab dose (0.5 mg/week) even in patients bearing very large adenomas and very high PRL levels.

Responsiveness to DA is very common but cannot be predicted with certainty (119). The attempt to create retrospectively a predictive score combining demographic, biochemical, and tumoral parameters was unsuccessful (120). Accordingly, it is worthwhile to begin treatment and monitor PRL values and tumor size. It has been reported that the first PRL values obtained during treatment (either evaluated as absolute value or as percent decrease from baseline or as lowering below a predefined threshold, according to different series) as well as early tumor shrinkage (with different cut-offs in different series) are good predictors of long-term DA efficacy (120), either evaluated at 6 months (121) or even earlier $(122,123,124)$. On the contrary, it was recently reported but not yet confirmed that heterogeneity of prolactinoma T2 signal at diagnosis could be used as a negative predictor factor of hormonal response to DA (87).

In responsive patients, Cab achieves progressive PRL decrease and tumor shrinkage for years, reaching hormone normalization and tumor shrinkage up to its disappearance or empty sella in most. In these highly responsive patients, Cab dose may be progressively lowered (to $0.25-0.5 \mathrm{mg} /$ week or even administered at longer intervals). On the other hand, a stepwise dose uptitration may be necessary in some resistant patients in whom the average Cab dose does not achieve hormonal and tumoral targets (125). An extreme uptitration (up to 7-12 mg/week) is anecdotic. It is reasonable to continue with further dose increase whenever this is followed by a substantial PRL decrease, whereas it is recommended to go back to the lowest dose that caused the lowest PRL levels without increase in tumor size, in order to avoid side effects.

Some patients experience an extremely rapid decrease in tumor size with a significant improvement in visual fields within 24-72 h. Improvements in visual fields generally parallel the changes observed at imaging, whereas reductions in PRL levels usually forerun any tumor shrinkage.

In MP patients, there is usually a positive correlation between PRL levels and adenoma size. In most cases, PRL reduction and tumor shrinkage follow a parallel course during Cab treatment, although there are exceptions: in some patients PRL decrease is faster than tumor size reduction, in others PRL decrease is accompanied by an improvement of visual fields without a significant change of tumor volume. In very rare cases, PRL levels decrease in spite of tumor size increase (95). 
Patients with persisting neuro-ophthalmologic symptoms, or tumor size increase/reincrease during treatment, or PRL reincrease despite carrying on treatment ('escape phenomenon') should be referred to neurosurgery (see below at 5.c).

Follow-up. In most severe cases, controls should be performed at short intervals:

- Neuro-ophthalmologic examination and clinical evaluation should be tightly evaluated within the first month in order to guide timing of neurosurgical interventions when needed.

- PRL levels should be evaluated weekly or monthly for the first 3 months and then at longer intervals if treatment is effective.

- MRI control should be performed according to ophthalmologic and PRL changes on treatment.

In less severe cases without visual impairment, biochemical, ophthalmologic and neuroradiological follow-up should be less aggressive, with the first evaluation after 3-6 months and the following according to clinical course: every 6-12 months in responsive patients and more tightly in partially responsive patients (3-6 months).

In patients whose PRL levels and tumor size are progressively reduced on DA treatment, the efficacy of treatment can be maintained even when DA dose is tapered.

Side effects, intolerance to treatment, and precautions to be taken (R 21-23) Most adverse events of DA are mild or moderate in severity.

The most typical side effects of DA are nausea, vomiting, postural hypotension, drowsiness, somnolence, nasal stuffiness, headache, Raynaud's phenomenon, and constipation. Nausea and postural hypotension occur frequently with $\mathrm{Br}$, even at the lowest doses at the beginning of treatment, and require shifting to Cab.

$\mathrm{Cab}$ is generally better tolerated than $\mathrm{Br}$, any side effect usually subsides over time but in a few cases (3-4\%) they may persist, requiring $\mathrm{Cab}$ downtitration or withdrawal and referral to neurosurgery.

Care should be exercised when administering DA concomitantly with other medications known to lower blood pressure. DA should be used with caution in patients with a history of neuropsychiatric disease.

DA-induced neuropsychiatric symptoms may be much more worrisome, including psychosis (or exacerbation of pre-existing psychosis) and ICD, such as compulsive gambling, shopping or eating, and hypersexuality, which resolved after either DA reduction or cessation $(126,127,128,129,130)$. These features can have devastating effects on the patient and his/her social environment. The exact incidence of DA-induced psychosis occurrence or exacerbation is not known but likely to be less than 1\% (56), whereas the true prevalence of ICD remains unclear. In an uncontrolled study of 308 patients with prolactinoma treated with $\mathrm{Cab}$ for at least 3 months, 17\% developed an ICD (131), a figure higher than in patients with non-secreting pituitary adenoma and no history of DA therapy and far lower than in patients with Parkinson's disease who usually are treated with higher doses of Cab. No association with DA type, dose, or duration of treatment was noted. A recent Australian paper evaluated specific neuropsychological questionnaires in 113 patients with hyperprolactinemia (prolactinoma in 95\%) and 99 normal controls and reported a $50 \%$ increase of relative risk in patients (up to $60 \%$ ) compared to a surprisingly high prevalence of ICD in the control group (40\%) (132). It has been suggested that patients (and family members/caregivers) should be forewarned of the possible development of ICD while on DA therapy.

In patients bearing large invasive MP extending through the sellar diaphragm and eroding the sellar floor, CSF nasal leakage has been rarely reported during DA treatment, either within the first few weeks or later after several months (34). This extremely severe complication is due to rapid tumor shrinkage that allows the leakage of CSF through an emerging tumor-induced gap in the skull base. The patient should be alerted to seek medical advice in case of watery nasal discharge. Analysis of fluid for beta-2 transferrin or beta trace protein is a wellknown, specific method for detecting the presence of CSF (133) but unfortunately it is not largely available. CSF leakage should prompt urgent evaluation by an ENT or a neurosurgeon (134).

$\mathrm{Cab}$ and pergolide (but not $\mathrm{Br}$ due to its lower affinity to serotonin 2B receptor) have been associated with valvular heart disease in patients with Parkinson's disease $(135,136,137)$. A recent meta-analysis observed a statistically significant increased risk of tricuspid valvular dysfunction with the use of Cab but in no patient tricuspid valve dysfunction was diagnosed as a result of clinical symptoms. In addition, there was no significant increase in any other valvulopathy (138). Neither treatment duration nor cumulative dosage was associated with an increased risk of tricuspid valve lesions of any severity and the clinical significance of these findings is therefore questionable. 
The use of the lowest effective dose of $\mathrm{Cab}$ and serial cardiac ultrasonographic examinations are suggested in patients taking larger doses of Cab. Current data do not support major concerns about the risk of valvulopathy in hyperprolactinemic patients who are chronically treated with DA at standard doses ( $\leq 2 \mathrm{mg} /$ week) (139). Subclinical valvular abnormalities detected by ultrasonography are not an indication for discontinuation of DA treatment. If valve lesions are detected during follow-up, further evaluation is indicated to distinguish Cab-induced etiology from other causes of valvulopathy.

\section{5.b.ii. How long to treat $(R 33,34,58,59)$ ?}

A major drawback of DA therapy is the potential need to keep the medication indefinitely in many patients. The optimal treatment strategy and duration of treatment is still not evident. It has been reported that starting treatment with high Cab doses to obtain a faster PRL normalization and tumor shrinkage is the best way to obtain disease remission (140), but data are still scanty on this topic.

In 2003, a landmark study (141) demonstrated that Cab could be withdrawn in a considerable proportion of selected patients. Recurrence of hyperprolactinemia and increase in tumor size were reportedly variable in several following studies after DA discontinuation. In a metanalysis of 19 studies with a total of 743 patients, the overall remission rate after DA withdrawal (defined as persistent normoprolactinemia after a 7-57-month follow-up) was only 21 and $16 \%$ for microP and MP, respectively (142). Another more recent metanalysis (143) showed that long-term disease remission rate in microP premenopausal women after the withdrawal of any DA was $36 \%$ (95\% CI, 21-52\%) and after the discontinuation of Cab was 32\% (95\% CI, 18-48). The remission rate was even lower in MP (28\%, 95\% CI 8-51\%).

Different studies reported that different factors are able to affect positively the success rate of DA withdrawal, such as the rate of PRL decrease after the start of DA treatment (120), tapering Cab dose before withdrawal (144), low-dose (0.5 mg/week) maintenance therapy for at least 1 year, restoration of a normal serum PRL level, and a significant reduction in tumor size or its disappearance (142, 143, 144). On the contrary, Cab treatment duration longer than 2 years was not a positive predictor (144) and parasellar invasion was a negative predictor (120).

In patients with MP guidelines from ES suggested that Cab could be withdrawn if normal PRL levels are maintained for at least 2 years despite progressive lowering of Cab dose and no visible tumor remnant on MRI (1). PRL levels should thereafter be monitored every 6-12 months to detect any later recurrence.

Some papers previously reported about the attempt of DA withdrawal after a first unsuccessful trial, with a success rate ranging $18-30 \%(145,146)$.

From a practical point of view, Cab treatment should not be withdrawn if PRL levels reincrease after lowering Cab dose, and the management should be different according to sex and tumor size.

- In microP, treatment should be lifelong in male patients to maintain normal sex hormones, whereas in females, it can be safely stopped after the menopause, when estrogen fall leads to the spontaneous normalization of PRL, allowing to stop prolonged follow-up in patients with a long history of PRL normalization.

- In MP, treatment should be lifelong and the attempt of withdrawal is only occasionally successful but requires anyway follow-up. The surgical option can be considered to obtain remission and allow the patient to get rid of any treatment.

After an attempt of withdrawal, PRL should be measured at 3 months and thereafter according to this first result. After withdrawal of DA therapy, the decision to repeat MRI may rely mostly on the degree of PRL elevation, arbitrarily set after a cut-off of $100 \mathrm{ng} / \mathrm{mL}$.

The delicate balance between the cost-effectiveness of a simple yearly monitoring of PRL levels on a minimal DA dose on the one hand and a more intensive biochemical and neuroradiological monitoring in the attempt to withdraw the treatment in patients with a MP remnant on the other hand should be individualized, taking into account also the impact of both strategies on QoL.

\section{5.b.iii. Restoration of gonadal function and fertility when and how $(R$ 40-42, 44)}

Hypogonadism is often present at diagnosis of PRLsecreting adenoma as PRL regulates gonadal steroid secretion. Chronically elevated PRL levels and hypogonadism are associated with reduced BMD and osteoporosis $(45,46)$. Moreover, untreated hypogonadism increases mortality in both sexes, due to cardiovascular diseases, while gonadal replacement therapy restores standard mortality rate $(147,148)$.

Even though DA very often obtain reversal of hypogonadism, especially in microP and MP with normal TSH-thyroid and ACTH-adrenal function (149), gonadal replacement therapy may be necessary in patients with persistent hypogonadism despite lowering/normalization of PRL levels or being resistant to DA. 
Premenopausal women In spite of estrogen sensitivity of lactotrophs, in microP patients using oral contraceptives or ERT, tumor size rarely increases even without DA treatment $(149,150,151)$. Women with microP who do not require fertility restoration may be treated only with estroprogestinic preparations (or estrogen alone in hysterectomized women) rather than DA.

Tumor growth is more concerning in patients with MP. Therefore, in cases with persistent amenorrhea a thorough case-by-case evaluation is required, with very close monitoring of tumor size and PRL levels if estrogen therapy is prescribed (151), due to the potential estrogeninduced decrease of DA efficacy. ERT should be continued at least until the age of physiologic menopause or longer evaluating the individual risk profile, taking into account the risk of osteoporosis.

DA treatment restores fertility in most women, even before menses occur (152). When normal menses are not restored, recombinant gonadotropins may be used for ovulation induction (149).

Males In males, impaired BMD and anemia are the main consequences of long-term PRL-induced hypogonadism. Commonly, normalization of PRL and testosterone levels improves anemia as well as other manifestations of hypogonadism and is associated with bone health status improvement (153).

There are not enough data regarding predictors of longlasting/persisting hypogonadism. In a recent retrospective study with a follow-up of only 2 years, hypogonadism persisted in $74 \%$ of patients after PRL normalization with Cab; the higher PRL levels and tumor size, the lower the chance of normalizing testosterone levels (154). In another study, long-term treatment (median: 3 years) was necessary to obtain normalization of hyperprolactinemia and reversal of hypogonadism (155).

Even though there is a potential risk that testosterone aromatization into estrogen could stimulate proliferation and hyperplasia of prolactinoma cells, thus inducing DA resistance (156), this occurrence is very rare (157), and the usefulness in this setting of aromatase inhibitors as add-on treatment was reported (158). TRT is thus indicated in case of hypogonadism persistence (159). Reports on the adequate timing for starting TRT are missing. Clinical experience suggests that in patients with pituitary failure, age-adjusted TRT should be quickly added to adrenal and thyroid replacement therapies, in order to improve clinical conditions and restore normal libido. As for isolated hypogonadism, an individual evaluation should guide the start of TRT. Given all these data, an early TRT may be suggested (within 3-6 months after the start of DA), provided that PRL levels are progressively decreasing and tumor size is shrinking.

TRT should be started soon also in patients partially sensitive to DA. In these cases, a tighter control of PRL levels (or MRI if needed) is suggested.

In male patients, treatment with clomiphene citrate or gonadotropins may be considered to restore or induce fertility, respectively. Clomiphene citrate increases serum testosterone levels and improves sperm motility, even in the absence of normal PRL levels (160).

\section{5.c. Neurosurgery feasibility and appropriateness (R 17-19, 26, 29, 30, 32)}

With the discovery of DA efficacy and the commercialization of $\mathrm{Br}$, medical therapy became the treatment of first choice for prolactinomas. In the '90s, medical therapy improved with Cab introduction (161).

Surgery was traditionally indicated as a second-line treatment in 14-38\% of prolactinoma patients (162) fitting certain conditions such as:

- resistance or escape to DA,

- intolerance to DA,

- in some psychiatric disorders worsened by DA treatment,

- spontaneous or DA-induced CSF leakage,

- patient's preference.

In the last two decades, a significant refinement in imaging and surgical techniques, particularly in TSS, has been attained in high-volume centers. Both microscopic and endoscopic pituitary surgery are minimally invasive techniques available for surgical treatment of pituitary adenomas (163). They have equally low complication rate and high cure rate. A recently published meta-analysis (164) shows that long-term disease remission is obtained in $74 \%$ of patients after surgery alone vs $37 \%$ after medication withdrawal. In microP, patients long-term remission was $36 \%$ after medication withdrawal and $83 \%$ after surgery. In $\mathrm{MP}, 60 \%$ of patients experienced long-term remission after surgery, compared to $28 \%$ after medical therapy withdrawal. Surgical results were not influenced by the surgical technique. These data mean that almost 60-70\% of patients under DA treatment cannot discontinue their medical therapy.

Literature published in the past 15 years shows favorable rates of postoperative normoprolactinemia in $71-100 \%$ of enclosed adenomas, particularly in microP (2). Remission 
rates ranges from 71 to $93 \%$ for microscopic series and from 82 to $100 \%$ for endoscopic series (2). Regarding MPs, the results are particularly good in enclosed adenomas, with early remission in $95 \%$ and long-term remission in $89 \%$ of the cases $(165,166)$.

The cure rate dramatically drops with the invasive character of prolactinomas (167). Endocrinological remission is inversely related to adenoma size, and it is $10 \%$ for giant or invasive tumors (168). Invasion of the cavernous sinuses and the highest level of preoperative hyperprolactinemia are the two best factors to predict a poor endocrinological outcome after surgery.

Considering both microP and MP, mortality in experienced hands in high-load centers is nearly $0 \%$ and major complications occur between 1 and $4 \%$ of patients (169) (Table 3).

Postoperative anterior pituitary failure is only occasionally reported in the majority of series, and menstrual cycles and fertility are usually restored if postoperative normalization of PRL is obtained in female patients. Reported complications of surgery are permanent diabetes insipidus in $2 \%(0-5 \%)$, meningitis in $1 \%$ (0-3\%), and CSF leakage in 3\% (2-5\%). Other endocrine complications are usually transient, such as diabetes insipidus in 16.5\% (7-28\%), inappropriate antidiuretic hormone $(\mathrm{ADH})$ secretion in 9\% (5-14\%), hypopituitarism in $2 \%(1-4 \%)$, namely central hypoadrenalism in $1-2 \%$, central hypogonadism in $3-6 \%$, and central hypothyroidism in 1-6\%. The overall complication rate was higher in the first cases pointing to a learning curve. New postoperative hormonal loss has been detected in $0 \%$ of patients with adenoma diameter $<20 \mathrm{~mm}$ and in $13.6 \%$ with adenoma diameter $\geq 30 \mathrm{~mm}$ (170). Improvement of pituitary function following surgery is relatively frequent, up to $35 \%$ in Kreutzer et al.'s series (169).

If less than $30-40 \%$ of patients can stop medication without recurrence of symptoms, a recurrence rate after surgery of up to $18 \%$ at 5 years can be expected (172).

Considering these results, a new role for surgery should be considered (162). Upfront TSS should be discussed at initial presentation in an individualized manner. The option of transsphenoidal resection if technically feasible should be offered to the patient with non-invasive adenoma with or without campimetric impairment. On the other hand, the invasive adenoma should be treated with DA, even in presence of severe visual impairment. In these cases, surgery should be a second-line treatment if DA are ineffective.

Another concerning point is the case of cystic prolactinomas: medical therapy is usually attempted, but

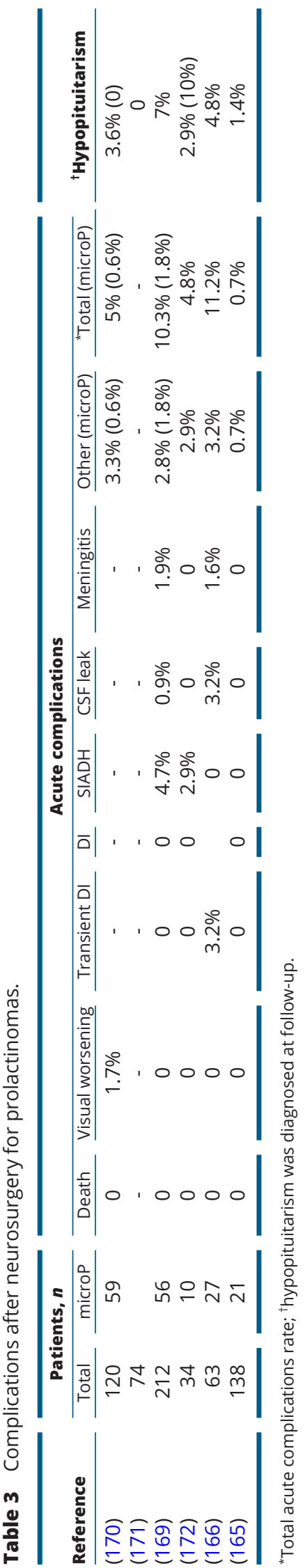

https://eje.bioscientifica.com 
poor shrinkage of cystic prolactinomas on DA therapy is not unusual, even though there are occasional reports of good results of medical treatment even in this setting (89, 174); such tumors might be treated surgically, particularly when a visual defect persists $(175,176)$.

It is well-known that prolactinomas in males are usually larger, more invasive, frequently with cystic components, and less sensitive to DA (8). This combination of factors suggests considering surgical treatment in this setting.

DA-induced tumor fibrosis is still a matter of discussion with conflicting reports about its real occurrence and the involved molecule ( $\mathrm{Br}$ in most cases) $(177,178,179)$.

The topic of aggressive tumors is addressed at 5.e.viii and of debulking of MP before pregnancy at 5.e.iii.

An issue to be considered is cost-effectiveness of surgery vs DA therapy: surgery is obviously associated with high upfront surgical costs due to hospitalization, but follow-up is very easy and cheap, based only on PRL sampling without routine MRI. DA treatment is conversely associated with accumulating, ongoing costs. At 10-year follow-up, surgery seems to be less costly and more effective than DA therapy (180), particularly in young patients, but there are no Italian data on this topic.

A recent meta-analysis of the available literature indicates that surgery is indeed a viable alternative firstline treatment for prolactinoma patients, especially for young microP female patients (164).

After surgery, MRI should be performed approximately after 3-4 months and further radiological follow-up strictly depends on PRL levels.

\section{5.d. Radiation treatments ( $35-38$ )}

Patients who have intolerance or resistance to DA often require surgery as a second-line approach. In such a clinical scenario, radiotherapy is usually reserved for patients after an unsuccessful surgical procedure who still have a tumor remnant resistant to DA or an uncontrolled tumor growth. Therefore, the clinical indications for radiation in patients with a PRL-secreting adenoma are, nowadays, rather limited.

The goal of radiotherapy in patients with prolactinoma is control of tumor growth. Normalization of PRL hypersecretion is an ancillary objective.

Old series on the long-term results of external beam fractionated radiotherapy typically found tumor control in over $80 \%$ of cases and normalization of PRL levels in $20-30 \%$ of the patients (reviewed in $(113,181)$ ).

At present, the most widespread technology to irradiate pituitary tumors is stereotactic radiosurgery using gamma knife or cyberknife or proton beam, which takes advantage of using a very focused and high-energy beam of radiation to the biological target in a single fraction. Following the widespread availability of gamma knife radiosurgery (GKRS) units from the '90s, more experience on the efficacy of GKRS in prolactinoma is slowly accruing.

A recent multicenter study collected the long-term results in 289 patients and showed tumor growth control in $95 \%$ of treated adenomas (5\% had tumor progression) at last follow-up (mean 60 months up to 267 months) and normalization of PRL levels in $43 \%$ of the patients at 5 years and $54 \%$ at 8 years (182). From a clinical standpoint, another relevant endpoint of GKRS in patients with partial resistance to DA is the normalization of PRL levels while continuing medical treatment. The endocrine remission rate of combined treatment approaches $50-70 \%$ at 5 years $(182,183,184)$.

The investigation of prognostic characteristics for endocrine remission after radiotherapy has been particularly difficult, probably because of the small sample size of most series. This problem has been circumvented in the multicenter study by Hung et al. (182). They found that higher PRL levels (namely $>270 \mathrm{ng} / \mathrm{mL}$ in their series) before GKRS were the only factor independently associated with an unsuccessful outcome.

A still unresolved issue is whether DA taken concomitantly may diminish the efficacy of radiation. Conflicting results have appeared $(182,183)$. Besides the problem of the retrospective nature of all studies and small sample size, the degree of the resistance to DA - partial or complete - probably contributes to the different results. Given the perduring uncertainty, some authors advocate for temporary 4-week discontinuation of DA to avoid a potential factor counteracting the effects of GKRS (181), but caution should be exercised and the dangers of a possible tumor expansion after drug withdrawal should be fully balanced, checking regularly PRL levels off DA treatment.

There is a need for serial MRI (and PRL) monitoring after radiation in most patients, every 3-6 months in the first year and thereafter according to initial response for at least a few years. When normalization of PRL levels is reached, the ongoing medical treatment with DA can be slowly tapered with the aim of a definitive withdrawal in those patients with persistent normal PRL levels.

As it is already standard of care after radiotherapy to the sellar region, the pituitary function should also be monitored as appropriate to document the development of hypopituitarism and start replacement treatment promptly (71). New hypopituitarism occurred in $25 \%$ of irradiated patients in the series by Hung et al. (182), namely 
$15,11,15$, and $6 \%$ for hypogonadism, hypoadrenalism, hypothyroidism, and GH deficiency, respectively. The onset of new hypopituitarism is mainly related to the dose at the stalk that should be maintained lower than 8-10 Gy.

The risk of rare but severe side effects after GKRS treatment seems very low, unless the patient had already received radiation therapy in the past. New visual damage was observed in 3\% of patients in the series by Hung et al. (182). Very recent studies show reassuring data on the risk of developing neurocognitive deficits (185) or brain neoplasms (186), even though follow-up was limited to 5 and 8 years for psychometric and oncologic evaluations, respectively.

\section{5.e. Special cases}

\section{5.e.i. Children (R 39)}

Due to rarity of prolactinomas in children, only small retrospective series are available. DA remain the firstline treatment in both microP and MP, the goals of this treatment being the restoration of normal gonadal function and tumor shrinkage (1). Br has been found to be effective in controlling PRL secretion in less than $70 \%$ of cases (187). Conversely, Cab (median dose of $2 \mathrm{mg} /$ week) has been found to be effective in normalizing PRL in most treated patients (74-87\%), tumor shrinkage being observed in up to $80 \%$ of cases $(16,188,189,190)$. A recent publication reported a worse response to $\mathrm{Cab}$ that was able to normalize PRL levels in 54\% of patients only (191).

Though the incidence of adverse events of DA has not been systemically investigated in the pediatric population, these are similar to those observed in the adults. While the most common gastrointestinal effects are nausea and vomiting that may lead to DA discontinuation in 3-5\% of pediatric patients, orthostatic hypotension is reported in up to $5 \%$ of them $(16,187,188,189,190,191)$.

DA resistance is associated with higher PRL levels and larger tumors (16). Interestingly, MEN-1 mutations seem to be an independent predictor of DA resistance in this group of patients (16), AIP mutations being less frequently found than in pediatric and adolescent patients with acromegaly/ gigantism (16).

The transsphenoidal surgical approach is mainly indicated in those patients not responding or intolerant to DA treatment (1). It is worth noting that surgical approach may be more difficult in little children due to anatomical reasons (188). The recurrence rate of prolactinomas after neurosurgery seems to be higher than that described in the adult population (30\% vs $20 \%$ ), this observation being in line with what observed in pediatric patients with other secreting pituitary adenomas $(191,192,193)$.
Few data are so far available on the effects of both radiotherapy and radiosurgery in pediatric population with prolactinomas. Salenave et al. observed PRL normalization in three out of four patients who received radiotherapy due to DA resistance and after surgical failure (16). Yang et al. described three patients who underwent GKRS, all showing $>90 \%$ reduction of tumor size and symptoms remission and no new onset of hypopituitarism being diagnosed during the follow-up (191).

GH treatment is rarely necessary because DA therapy is generally sufficient to normalize GH deficiency and to restore growth (16). In children with tumor remnant needing GH replacement therapy, a tighter follow-up is needed.

\section{5.e.ii. Women requiring contraception or sex hormone replacement therapy ( $R$ 41-43)}

Attempts to link the progression of PRL-secreting adenomas to oral contraceptive use have recently proved negative and many studies have excluded this correlation $(150,194,195,196)$.

Women who do not wish to conceive should practice a reliable method of contraception. The safety of estroprogestinic pill was demonstrated in women with microP whose cycles were restored by DA treatment (151). In these cases, estroprogestinic pill may be considered as the only treatment of the disease. At variance, in DA nonresponder MP patients, the persistence of amenorrhea, symptoms of hypogonadism, and the control of tumor growth are an issue. Since ERT may cause a decrease in the efficacy of DA, the evaluation of PRL secretion before and after the start of replacement therapy and the careful measurement of adenoma size by MRI over the first year are warranted, while continuing DA therapy (151). In these cases, the lack of tumor shrinkage may be acceptable as long as no tumor growth is observed. However, further prospective studies including large numbers of patients are needed to validate this practice.

\section{5.e.iii. All about pregnancy from ovulation to breastfeeding} (R 44-57)

Before conception Approximately 90\% of women with hyperprolactinemia will start ovulating within a few weeks after the start of DA treatment (113).

Neurosurgical option for microP and enclosed MP to avoid DA and for MP in DA-resistant patients (mostly if close to optic pathways) to avoid symptomatic enlargement during pregnancy should be discussed with the patient $(162,197)$ 
It is recommended to plan pregnancy. The treatment, either DA or surgery, should lower PRL levels to allow conception and in case of MP should shrink tumor within sellar limits in order to minimize the risk of enlargement during pregnancy. It is recommended to perform MRI prior to conception in MP to confirm the shrinking efficacy of DA treatment.

In microP, any attempt at conception should be postponed at least until the first DA-induced menstrual cycle. Successful pregnancy is common after DA treatment (197, 198, 199), but gonadotropins can be used to revert hypogonadotropic hypogonadism if DA are unsuccessful.

During pregnancy In normal pregnancy, pituitary gland volume is increased by about $70 \%$ and PRL levels increase. PRL does not reliably reflect an increase in tumor size and thus is not useful for clinical assessment (197). An increase in tumor size correlates better with clinical symptoms, such as headaches or visual disturbances.

$\mathrm{Br}$ and $\mathrm{Cab}$ are classified as pregnancy risk factor $\mathrm{B}$ (animal reproduction studies failed to demonstrate a risk to the fetus and there are no adequate and well-controlled studies in pregnant women) and have been shown to cross the placenta (200). Accordingly, DA should be stopped at confirmation of pregnancy (if not already discontinued before). In this way, there will be exposure to DA for only about 3-4 weeks of gestation.

Microprolactinoma. The risk of significant tumor growth during pregnancy is less than $3 \%(197,198)$. The patient should be followed clinically during pregnancy (197). Visual field testing should be carried out in patients who develop symptoms and MRI when intervention may be indicated.

Macroprolactinoma. The management and prognosis of DA-treated MP during pregnancy remains unclear. Few case series have been reported but the risk of symptomatic tumor enlargement (with headache and visual loss due to pressure effect on the optic chiasm) is high $(197,198$, 201 ): up to $20-30 \%$ of women with no prior surgery or irradiation and in the range of 5\% of those previously operated on or irradiated (197). In a recent two-center, retrospective, observational study, a total of 85 viable pregnancies were observed in 46 patients with MP (201). Tumor growth-related symptoms were identified 12 times in 9 patients, including 3 cases of apoplexy. Restarting, changing, and/or increasing DA treatment was effective in 10 cases. Emergency surgery had to be performed twice (due to pituitary apoplexy). Patients with tumor progression tended to present with larger tumors after initial treatment and before pregnancy, whereas adenoma size at diagnosis did not seem to be a significant predictive factor (201). The obstetrical outcomes were comparable to the general population.

The patient with a small intrasellar or inferiorly extending macroadenoma can probably be managed as those with microadenomas (197). Close clinical monitoring should be undertaken with formal visual field testing during each trimester (197). The continuation or reinstitution of therapy should be considered in the case of large pituitary tumors particularly if the adenoma is in close vicinity to the optic chiasm or signs of tumor expansion develop during pregnancy $(197,198,202)$. Due to its higher efficacy and better tolerability, Cab is preferable in these cases (202).

In a small proportion of those cases, tumor enlargement reflected apoplexy, which may require an entirely different management course according to specific guidelines, including surgery and hormone replacement for hypopituitarism. MRI may be very helpful in distinguishing between hemorrhage from a tumor vs simple tumor enlargement.

Since a slight increase in risks of stillbirths and neonatal deaths was shown with first trimester Gd exposure (203), it is recommended not to use Gd throughout pregnancy, whereas MRI can be performed safely after the fourth month only for particular circumstances, such as uncontrolled worsening disease with severe headache, visual impairment, or cranial nerve palsies.

Any surgical procedure during pregnancy results in a 1.5-fold increase in fetal loss in the first trimester and a 5 -fold increase in the second trimester (197). Emergency surgery for sellar/parasellar lesion caused abortion in 1 out of 6 cases reported by Zoli et al. and in 2 out of 25 in their systematic literature review (204).

The risks of congenital malformations during the first trimester and those of premature birth during the third trimester led to a preference for the second trimester to consider surgery. Although limited, surgical risks remain difficult to assess (205). In the third trimester, preterm delivery should be considered (202).

In conclusion, the management should be individually tailored, taking into account the severity of symptoms at presentation, disease progression, and surgical expertise available, with a fine balance between the risks for the mother and the risk of surgery for the baby (206). 
Delivery If there are not obstetric contraindications, vaginal delivery can be safely performed in women with microadenoma (201).

The risk of apoplexy should be carefully considered together with the obstetrician when evaluating the modality of delivery, vaginal or cesarean, in the patient with symptomatic macroadenoma (201).

Obstetrical outcome Data regarding less than 6-week exposure to DA have been reported in more than 6000 and 1000 pregnancies for $\mathrm{Br}$ and $\mathrm{Cab}$, respectively, with no increase in spontaneous abortions, preterm deliveries, multiple births, or congenital malformations compared to general population (152). Namely, malformations were reported in $3.4 \%$ of $\mathrm{Cab}$ exposed pregnancies vs $6.4 \%$ in the general population (207).

Maternal and fetal outcomes in Cab-induced pregnancies are reassuring also in recent series $(199,208$, 209). On the contrary, higher miscarriage rate was reported in those patients treated with Cab throughout pregnancy for tumor volume increase (209).

There are just over 100 women reported to have used $\mathrm{Br}$ throughout gestation (210) and no abnormalities in their infants were found, except for two cases with minor malformations. Use of $\mathrm{Cab}$ throughout gestation is described in 15 women (211), with 1 preterm delivery and 1 intrauterine death.

Breastfeeding Although suckling stimulates PRL secretion in normal women, there are no data to suggest that breastfeeding can cause tumor growth (208). On the contrary, nursing caused neither an increase in PRL levels nor headaches or visual disturbances, which would suggest tumor enlargement (197). Accordingly, breastfeeding should be allowed in patients with uneventful pregnancies, postponing the possible restart of DA treatment $(152,211)$.

After pregnancy A retrospective study conducted in two Belgian academic centers including 73 patients (54 microPs and 19 MPs) reported normal PRL levels without medication in more than $40 \%$ (both microP and MP) of women previously diagnosed with prolactinoma and followed-up until a median of 22 months after pregnancy and lactation (212).

A recent series confirmed that approximately a quarter of women with prolactinoma will have normal PRL levels without treatment after pregnancy (199). The likelihood of remission was associated with a smaller initial adenoma size, lower PRL levels at diagnosis and postpartum, and older maternal age $(199,212)$. The number of pregnancies per woman as well as breastfeeding and its duration did not influence remission rate (198, $208,212)$. In case of remission, clinical and hormonal follow-up at 6 months after delivery and yearly thereafter has been recommended (202).

\section{5.e.iv. Postmenopausal women (R 58-59)}

Most MP patients in postmenopausal age show response to DA therapy with PRL level normalization and adenoma shrinkage $(115,152)$.

Menopause may have a beneficial effect on the natural history of prolactinoma patients (152). In some studies, untreated patients with microP during menopause had spontaneous normalization of PRL levels and disappearance of the tumor (213). As a further confirmation of the favorable impact of menopause, the relapse of hyperprolactinemia after DA withdrawal in microP is nearly $30 \%$ in postmenopausal patients (far lower than the $70 \%$ reported in premenopausal women) (152).

Serum PRL levels detected 6-12 months after DA withdrawal are a useful predictor of subsequent trend that can guide clinical practice both in microP and MP. Tumor progression may occur in nearly $7 \%$ of patients with microP and PRL levels may reincrease in MP. Therefore, a regular follow-up is required in patients showing increasing hyperprolactinemia that should be treated according to standard clinical practice (213).

\section{5.e.v. Women with personal or familial history of breast cancer (R 60)}

Experimental data showed that PRL receptors are expressed on breast cancer cells (214) and that PRL does not induce breast carcinogenesis but has a positive effect on breast cancer progression in animals (215).

Pathophysiologic data showed that PRL levels in the higher quartile of the normal range are associated to increased risk of breast cancer and invasiveness, particularly in postmenopausal women (216), and that the addition of PRL levels (even within the normal range) improves the predictive value of traditional risk factors for breast cancer (217).

Notwithstanding these experimental data and pathophysiologic premises, epidemiologic studies did not show any increase of breast cancer, either in patients with prolactinomas or idiopathic hyperprolactinemia from 
Netherlands, Sweden, and Denmark (218) or in patients treated with antipsychotic drugs (219).

We can speculate that hyperprolactinemia-induced hypogonadism might have a protective effect against breast cancer.

\section{5.e.vi. Patients with a psychiatric disease (R 61-63)}

It is well-known that treatment of several psychotic disorders is based on drugs that act as dopamine antagonists. As a consequence, the treatment with antipsychotic drugs might cause hyperprolactinemia. The workup of a suspected drug-induced hyperprolactinemia has been already discussed (at 4.b.).

Treatment of symptomatic neuroleptic-induced hyperprolactinemia aims to restore menses and sexual function without causing a flare-up of psychosis. Accordingly, the management of hyperprolactinemia in psychiatric patients needs a tight collaboration between endocrinologists and psychiatrists, with the joint evaluation of individual drug need and selection. Different approaches should be considered in symptomatic patients (79). Whereas the use of DA to treat neurolepticinduced hyperprolactinemia might cause worsening of psychiatric symptoms, as reported in a few cases (220), on the other hand, small series did not report exacerbation of psychosis when small doses of DA were used (221). In addition, estroprogestinic treatment may be used to treat hypogonadism in women, whereas the use of testosterone in men should be approached with extreme caution.

The association between psychotic disorders and prolactinoma is rare. A multicenter retrospective study collected data from 1987 to 2017 of 18 patients affected with both severe psychotic disorder and MP (222). The question raised by this retrospective study is whether DA may reduce the efficacy of antipsychotic drugs in psychiatric patients affected with MP. Each patient required both antipsychotic drugs for her/his psychiatric disease and DA for treating the MP. Among the psychiatric relapses requiring admission in psychiatric units that were observed in nine patients during the follow-up period, none could be certainly imputed to the use of DA. Combined treatment with antipsychotic drugs and DA shrank MP in a high percentage $(87.5 \%)$ of cases, even though the magnitude of tumor size reduction was smaller than that observed in patients without a psychiatric disease. Only $25 \%$ of patients reached normal PRL levels. Although a strong relationship was not demonstrated, the efficacy and safety of DA in a psychiatric patient affected with a prolactinoma should be individually evaluated.

\section{5.e.vii. Treatment of osteoporosis (R 64)}

The treatment of prolactinoma with DA normalizes serum OC levels, a parameter of bone formation, decreases NTX levels, a bone resorption marker (39), improves BMD, and prevents further bone loss by reducing PRL levels and by restoring the functionality of the gonadal axis $(39,43,46$, 223, 224).

There are no prospective controlled studies regarding the effect of the treatment of hyperprolactinemia on the outcome of fracture risk. In a meta-analysis, vertebral fractures were reported in $46 \%$ of untreated female patients vs $20 \%$ of patients on Cab (OR: 0.29 ; $95 \%$ CI: $0.10-0.78$ ) and in $67 \%$ of untreated male patients vs $26 \%$ in Cab-treated patients (OR: 0.18; 95\% CI: 0.03-0.94), with no difference between eugonadal and hypogonadal men $(P=0.8)(225)$. This suggests a beneficial effect of DA treatment on fracture risk. Patients with prolactinoma had a significantly higher relative risk of fractures compared to normal controls before the diagnosis $(\mathrm{RR}=1.6)$ but not after diagnosis $(\mathrm{RR}=1.2)$ (50). However, the prevalence of vertebral fractures remains higher in men treated for prolactinomas than in the ageand gender-matched control population (48).

Even though normalization of PRL concentrations by DA therapy can improve BMD and can reduce the risk of fracture, it may be necessary to treat specifically osteoporosis with the same therapeutic options as in the general population in addition to the treatment for hyperprolactinemia. Furthermore, in light of the recent evidence of a detrimental direct effect of hyperprolactinemia on bone, osteoporosis and the risk of fracture might change the indications for treatment with DA, especially in postmenopausal women (226) and in patients with iatrogenic hyperprolactinemia, but more data are needed.

5.e.viii. Resistance to treatment and aggressive disease from definition to multimodal treatment ( $R$ 65-69)

A universal consensus on the definition of DA resistance is still lacking, even though the widely accepted definition is a failure to normalize PRL on maximally tolerated doses of DA and a failure to achieve at least $50 \%$ tumor size reduction (227). The maximally tolerated doses vary among patients: doses up to $12 \mathrm{mg}$ weekly and $30 \mathrm{mg}$ daily were anecdotally reported for $\mathrm{Cab}$ and $\mathrm{Br}$, respectively $(113,120,228)$. In common clinical practice, the mean maximum dose of $\mathrm{Cab}$ is around $4 \mathrm{mg}$ per week (109). Even though no agreement exists about the minimum duration of treatment to define resistance, it was suggested at least 6 months on the highest tolerated DA dose (229). 
A subset of individuals with prolactinomas will exhibit a varying degree of resistance to DA $(109,228)$. Some patients may respond poorly to one DA but well to another or individuals may respond well initially and later become drug resistant and show a recurrence of the disease. Cases of 'selective' resistance have been reported in a few patients in whom the drug induces discordant PRL-lowering and tumor size-reducing effects.

Resistance is more frequent in cases of MP, invasive tumors, and male patients. Other factors are very young age, cystic, hemorrhagic and/or necrotic components (before the start of pharmacological treatment) inside the tumor, and genetic predisposition to develop pituitary tumors such MEN-1 or AIP mutations $(228,230,231)$.

The estimated prevalence of resistant prolactinomas is approximately $20-30 \%$ for $\mathrm{Br}$ and $10 \%$ for $\mathrm{Cab}$ (228). In poor responders, Cab doses higher than $3.5 \mathrm{mg}$ weekly could achieve a controlled PRL within 1 year (120). In resistant prolactinomas, PRL normalization could be achieved in $26 \%$ of patients with some degree of tumor shrinkage in $52 \%$ of them by receiving at least daily Cab therapy (>3.5 mg/week) (109).

In patients with Cab-resistant prolactinomas, a $\mathrm{Br}$ trial was anecdotally reported as a safe and well-tolerated alternative (110).

Patients partially resistant to medical treatment may benefit from neurosurgery, even though tumor resection is likely incomplete. Surgical debulking may improve hormonal control with lower postoperative doses of Cab $(109,166)$. Radiotherapy should be offered to patients who still do not respond to DA treatment after unsuccessful surgery (228). Surgery can be repeated in resistant/ aggressive cases.

PRL-secreting tumors frequently express somatostatin receptors (SSTR), particularly SSTR5 and SSTR1 and to a lesser extent SSTR2 (232). Very preliminary data support that in some patients with DA-resistant MP, the addition of octreotide LAR or pasireotide LAR to ongoing Cab therapy may result in significant reductions in tumor volume and PRL levels $(233,234)$.

Neuroradiological monitoring of resistant prolactinomas is performed on a case-by-case basis. Up to $30 \%$ of aggressive MPs do not respond with significant shrinkage to Cab (228).

In a minority of patients with complete resistance to DA treatment and unsuccessful surgery and radiation therapy, the tumor may show unrelenting and rapid growth $(1,235)$. In rare cases, patients may develop the presence of distant metastases, either through dissemination into the CSF or to other organs (pituitary carcinoma). The therapeutic options in patients with an aggressive prolactinoma or a pituitary carcinoma are rather limited. The first option is chemotherapy with the alkylating agent temozolomide. In a recent survey of the European Society of Endocrinology that collected the data on 165 patients who had been treated with temozolomide (236), prolactinomas accounted for $20 \%$ of all aggressive pituitary tumors and for $37.5 \%$ of all pituitary carcinoma. A positive response to temozolomide, defined as complete, partial, or stable disease, was reported in $79 \%$ of all patients and was independent of tumor type (hormone active or inactive).

Patients who had progression of disease during temozolomide treatment or who had recurrence of disease after an initial response had a grim prognosis. Therapeutic options in this setting are very limited. Other chemotherapeutic agents or immunotherapy have been tried but the results have been poor or short-lived. Peptide receptor radionuclide therapy is another last resort treatment for such patients. However, few cases of prolactinomas are reported with mixed results (237).

\section{5. f. Therapeutic strategy possible shift to surgery as first-line option (R 16-20, 25-27, 33)}

Medical therapy with DA is still considered the first therapeutic option of hyperprolactinemic states (1) because it can obtain restoration of eugonadism and tumor control with disappearance of neurological and ophthalmologic symptoms in most patients. It is however unable to attain the remission of the disease in most patients (143). On the contrary, neurosurgery, still considered as ancillary to medical treatment to be employed only in resistant or aggressive cases, thanks to its technological improvement could be a viable alternative, because it is able to obtain disease remission in the majority of patients with enclosed adenomas, with a very low risk of long-term complications $(2,165,166)$. Neurosurgery can thus be regarded as the first option in selected clinical settings.

In centers with experienced neurosurgeons, the possibility of cure by upfront surgery vs life-long DA therapy should be discussed by the endocrinologist and the neurosurgeon with all patients in an individualized manner. The patient should be informed that drug therapy is safe and effective, can obtain restoration of eugonadism, can cause disappearance of neuro-ophthalmologic symptoms, and lead to tumor shrinkage in most, without causing any loss of pituitary function, but it is often 
lifelong. On the other hand, surgery in selected cases offers the real possibility to cure the disease.

Surgery should be particularly considered for noninvasive microP in which a very high cure rate (even over $80 \%$ in the best hands) can be anticipated (2) and in circumscribed MP given the high cure rates, comparable to microP. The will of an informed patient is an important indication for first-line TSS $(1,172,238)$.

In large prolactinomas with invasive character, DA therapy should be initially preferred due to the low cure rate and the increased risk of surgery in this setting (165, $169,239)$. Whenever DA treatment does not revert neuroophthalmologic symptoms quickly, the patient should be rapidly referred to neurosurgery.

Prolactinomas in male patients may behave more aggressively and show an increased likelihood of resistance to DA treatment. Hence, a giant/macroadenoma, mostly in a male patient, is a strong indication to a tight follow-up and may swing the pendulum in favor of surgery, provided that a trial of DA treatment had no effect on tumor-related symptoms (240).

Young age is another important aspect to be considered in proposing surgical treatment to minimize the cumulative dose of DA $(136,180)$.

The patients' wish to become pregnant is a re-enforcing argument if surgery is considered. In microP, surgery offers a high likelihood of cure and the opportunity to become pregnant without DA medication. Surgery should be of course performed by a skilled operator, to minimize the risk of pituitary damage and fertility impairment. In MP, if the patient is not willing to wait for DA results, pre-pregnancy debulking significantly reduces the risk of symptomatic enlargement during pregnancy $(165,241)$.

Concerning aggressive prolactinomas, it is conceivable that a combination of the different treatment modalities (DA, surgery, radiotherapy, and temozolomide) will afford the best results, but firm data are lacking on this topic.

Finally, it is worthwhile considering that prolactinomas are the most frequent pituitary tumors and microPs account for the majority of them. The indication for surgery should thus take into account the large prevalence of the disease and the need to refer patients to high-volume neurosurgical centers with expertise in pituitary surgery.

\section{Conclusions and perspectives}

We are facing a paradigm change in the management of prolactinomas. Both DA and neurosurgery might now be regarded as a first-line therapeutic option in certain clinical and neuroradiological scenarios, such as a non-invasive adenoma, regardless of size. In this clinical situation and when feasible, a shared decision should be implemented with full provision of information about benefits and risks of both treatment options, taking into account patient's

\section{Box 1. Tips and tricks}

1. Serum prolactin (PRL) should be measured only in specific clinical settings, such as menstrual disturbances, erectile dysfunction, loss of libido, infertility, or imaging showing a lesion in the hypothalamic-pituitary region.

2. The insertion of an i.v. catheter 15-20 min before sampling for PRL assay in the diagnostic phase is a simple and practical tool for the confirmation of diagnosis in cases of mild hyperprolactinemia $(<80-100 \mathrm{ng} / \mathrm{mL})$.

3. Try to identify the cause of hyperprolactinemia, including iatrogenic and other causes different from PRL-secreting tumors (see text for details).

4. Do not start treatment with dopamine agonist (DA) drugs without a diagnosis and a pituitary MRI if appropriate.

5. The magnitude of PRL levels in macroadenomas often enables to differentiate between 'true' prolactinomas and 'pseudoprolactinomas' (see text for details).

6. The management should be guided by clinics and not only by 'numbers'.

7. Patient's wishes should be taken into account in the management.

8. Do not forget hypopituitarism.

9. Single PRL measurement is adequate during DA treatment.

10. In patients on chronic DA treatment, no particular timing is required for PRL sampling.

11. During intercurrent illness or scheduled hospitalization, chronic DA treatment should be continued.

12. Alert the patient and caregivers about the possible DA-induced impulse control disorder.

13. Advice female patients to plan pregnancy and provide easily accessible medical support to pregnant women.

14. The choice about delivery and breastfeeding should be shared with the endocrinologist.

15. In complex cases, do not hesitate to refer patient to experts: aggressive tumors should be treated by a pituitary multidisciplinary team. 
preferences and values. Whereas most endocrinologists are potentially able to manage DA treatment, reported data clearly show that the best surgical results are obtained by neurosurgeons with a high caseload of pituitary operations (at least 50 pituitary operations per year) $(242,243,244)$.

An integrated network among hub and spoke centers able to manage even complex cases in multidisciplinary teams should be implemented.

\section{Declaration of interest}

The following authors disclose competing interests in the past 2 years: Alessandro Bozzao, Marco Caputo, Laurence Kaznelson, Giovanni Lasio, Marco Losa, Davide Milani, Catalina Poiana, and Michele Zini report that they do not have any relevant financial relationships with any commercial interests. Maria Rosaria Ambrosio reports registration fees for scientific meetings from Ipsen, Novartis, Pfizer, and Savio Pharma. Roberto Attanasio reports registration fees for scientific meetings from IBSA, Pfizer, and Novartis. Claudia Battista reports registration fees for scientific meetings from Ipsen and Eli Lilly. Enrica Ciccarelli reports registration fees for scientific meetings from Novartis. Renato Cozzi reports that he has been a member of the Advisory Board of Novartis, received research fees for scientific meetings or oral presentations from Ipsen, Italfarmaco, and Novartis. Laura De Marinis reports that she has been Principal Investigator for clinical trials for Novartis, Ipsen, Pfizer, and Chiasma. Ernesto De Menis reports registration fees for scientific meetings from Novartis, Ipsen, and Pfizer. Marco Faustini Fustini is a member of the Advisory Board of Pfizer. Franco Grimaldi received honoraria and had roles as consultant or advisor from Ipsen, Pfizer, Novartis, Advanced Accelerator Applications - AAA. Andrea Lania reports that he is a member of the Advisory Board of Novartis, received research grant support from Novartis, and registration fees for scientific meetings from IBSA, Pfizer, Novartis, and Shire. Francesco Logoluso has been a member of the Advisory Board of Novartis and received registration fees for scientific meetings from Ipsen, Pfizer, Novartis, IBSA, and Shire. Anton Luger: receipt of honoraria and/or consultation fees from Ipsen, Merck Serono, Novartis, Pfizer, Sandoz and grants or research support to the Clinical Division of Endocrinology and Metabolism, Department of Medicine III, University of Vienna from Ipsen, Novartis, Pfizer. Pietro Maffei reports that he has been a member of the Advisory Board of Novartis and Pfizer, received research fees for scientific meetings or oral presentations from Pfizer, Novartis, and Ipsen. Maurizio Poggi reports registration fees for scientific meetings from Novartis, Eli Lilly, and Ipsen.

\section{Funding}

This work did not receive any specific grant from any funding agency in the public, commercial, or not-for-profit sector.

\section{Acknowledgements}

The authors also thank Piero Picozzi (IRCCS Humanitas Research Hospital, Rozzano, Italy) for the critical reviewing of the section on radiotherapy.

\section{References}

1 Melmed S, Casanueva FF, Hoffman AR, Kleinberg DL, Montori VM, Schlechte JA, Wass JA \& Endocrine Society. Diagnosis and treatment of hyperprolactinemia: an Endocrine Society clinical practice guideline. Journal of Clinical Endocrinology and Metabolism 201196 273-288. (https://doi.org/10.1210/jc.2010-1692)
2 Tampourlou M, Trifanescu R, Paluzzi A, Ahmed SK \& Karavitaki N. Therapy of endocrine disease - surgery in microprolactinomas: effectiveness and risks based on contemporary literature. European Journal of Endocrinology 2016175 R89-R96. (https://doi.org/10.1530/ EJE-16-0087)

3 Lopes MBS. The 2017 World Health Organization classification of tumors of the pituitary gland: a summary. Acta Neuropathologica 2017 134 521-535. (https://doi.org/10.1007/s00401-017-1769-8)

4 Atkins D, Best D, Briss PA, Eccles M, Falck-Ytter Y, Flottorp S, Guyatt GH, Harbour RT, Haugh MC, Henry D et al. Grading quality of evidence and strength of recommendations. BMJ $2004 \mathbf{3 2 8} 1490$. (https://doi.org/10.1136/bmj.328.7454.1490)

5 Swiglo BA, Murad MH, Schünemann HJ, Kunz R, Vigersky RA, Guyatt GH $\&$ Montori VM. A case for clarity, consistency, and helpfulness: state-ofthe-art clinical practice guidelines in endocrinology using the grading of recommendations, assessment, development, and evaluation system. Journal of Clinical Endocrinology and Metabolism 200893 666-673. (https://doi.org/10.1210/jc.2007-1907)

6 Guyatt GH, Oxman AD, Vist GE, Kunz R, Falck-Ytter Y, AlonsoCoello P, Schünemann HJ \& GRADE Working Group. GRADE: an emerging consensus on rating quality of evidence and strength of recommendations. BMJ 2008336 924-926. (https://doi.org/10.1136/ bmj.39489.470347.AD)

7 Fitch K, Bernstein SJ, Aguilar MD, Burnand B, LaCalle JR, Lazaro P, Van Het Loo M, McDonnell J, Vader JP \& Kahan JP. The Rand/UCLA Appropriateness Method User's Manual. CA: RAND. (available at: https ://www.rand.org/content/dam/rand/pubs/monograph_reports/2011/ MR1269.pdf). Last accessed on 11 June 2021.

8 Chanson P \& Maiter D. The epidemiology, diagnosis and treatment of prolactinomas: the old and the new. Best Practice and Research: Clinical Endocrinology and Metabolism 201933 101290. (https://doi. org/10.1016/j.beem.2019.101290)

9 Vroonen L, Daly AF \& Beckers A. Epidemiology and management challenges in prolactinomas. Neuroendocrinology 2019109 20-27. (https://doi.org/10.1159/000497746)

10 Buurman H \& Saeger W. Subclinical adenomas in postmortem pituitaries: classification and correlations to clinical data. European Journal of Endocrinology 2006 154 753-758. (https://doi.org/10.1530/eje.1.02107)

11 Samperi I, Lithgow K \& Karavitaki N. Hyperprolactinemia. Journal of Clinical Medicine 20198 2203. (https://doi.org/10.3390/jcm8122203)

12 Shimon I. Giant prolactinomas. Neuroendocrinology 2019109 51-56. (https://doi.org/10.1159/000495184)

13 Olarescu NC, Perez-Rivas LG, Gatto F, Cuny T, Tichomirowa MA, Tamagno G, Gahete MD \& on behalf of EYRC. Aggressive and malignant prolactinomas. Neuroendocrinology 2019109 57-69. (https://doi.org/10.1159/000497205)

14 McNeill KA. Epidemiology of brain tumors. Neurologic Clinics 201634 981-998. (https://doi.org/10.1016/j.ncl.2016.06.014)

15 Hoffmann A, Adelmann S, Lohle K, Claviez A \& Müller HL. Pediatric prolactinoma: initial presentation, treatment, and long-term prognosis. European Journal of Pediatrics 2018177 125-132. (https:// doi.org/10.1007/s00431-017-3042-5)

16 Salenave S, Ancelle D, Bahougne T, Raverot G, Kamenicky P, Bouligand J, Guichon-Mantel A, Linglart A, Souchon PF, Nicolino M et al. Macroprolactinomas in children and adolescents: factors associated with the response to treatment in 77 patients. Journal of Clinical Endocrinology and Metabolism 2015100 1177-1186. (https:// doi.org/10.1210/jc.2014-3670)

17 Soto-Pedre E, Newey PJ, Bevan JS \& Leese GP. Morbidity and mortality in patients with hyperprolactinemia: the PROLEARS study. Endocrine Connections 20176 580-588. (https://doi.org/10.1530/EC-17-0171)

18 Lamba N, Noormohamed N, Simjian T, Alsheikh MY, Jamal A, Doucette J, Zaidi H, Smith TR \& Mekary RA. Fertility after transsphenoidal surgery in patients with prolactinomas: a metaanalysis. Clinical Neurology and Neurosurgery 2019 176 53-60. (https:// doi.org/10.1016/j.clineuro.2018.11.024) 
19 Goldstein I, Kim NN, Clayton AH, DeRogatis LR, Giraldi A, Parish SJ, Pfaus J, Simon JA, Kingsberg SA, Meston C et al. Hypoactive sexual desire disorder: International Society for the Study of Women's Sexual Health (ISSWSH) expert consensus panel review. Mayo Clinic Proceedings 201792 114-128. (https://doi.org/10.1016/j. mayocp.2016.09.018)

20 Bernard V, Young J, Chanson P \& Binart N. New insights in prolactin: pathological implications. Nature Reviews: Endocrinology 201511 265-275. (https://doi.org/10.1038/nrendo.2015.36)

21 Kleinberg DL, Noel GL \& Frantz AG. Galactorrhea: a study of 235 cases, including 48 with pituitary tumors. New England Journal of Medicine 1977296 589-600. (https://doi.org/10.1056/NEJM197703172961103)

22 Huang W \& Molitch ME. Evaluation and management of galactorrhea. American Family Physician 201285 1073-1080.

23 De Rosa M, Zarrilli S, Di Sarno A, Milano N, Gaccione M, Boggia B, Lombardi G \& Colao A. Hyperprolactinemia in men: clinical and biochemical features and response to treatment. Endocrine 200320 75-82. (https://doi.org/10.1385/ENDO:20:1-2:75)

24 Tirosh A, Benbassat C, Lifshitz A \& Shimon I. Hypopituitarism patterns and prevalence among men with macroprolactinomas. Pituitary 201518 108-115. (https://doi.org/10.1007/s11102-014-0563-z)

25 Fideleff HL, Boquete HR, Suárez MG \& Azaretzky M. Prolactinoma in children and adolescents. Hormone Research 200972 197-205. (https:// doi.org/10.1159/000236081)

26 Al Sabie F, Tariq Z, Erickson D \& Donegan D. Association between prolactinoma and body mass index. Endocrine Practice 202127 312-317. (https://doi.org/10.1016/j.eprac.2020.09.001)

27 Andereggen L, Frey J, Andres RH, Luedi MM, Gralla J, Schubert GA, Beck J, Mariani L \& Christh E. Impact of primary medical or surgical therapy on prolactinoma patients' BMI and metabolic profile over the long-term. Journal of Clinical and Translational Endocrinology 202124 100258. (https://doi.org/10.1016/j.jcte.2021.100258)

28 Creemers LB, Zelissen PM, van't Verlaat JW \& Koppeschaar HP. Prolactinoma and body weight: a retrospective study. Acta Endocrinologica 1991125 392-396. (https://doi.org/10.1530/ acta.0.1250392)

29 Greenman Y, Tordjman K \& Stern N. Increased body weight associated with prolactin secreting pituitary adenomas: weight loss with normalization of prolactin levels. Clinical Endocrinology 199848 547-553. (https://doi.org/10.1046/j.1365-2265.1998.00403.x)

30 Hayashi Y, Sasagawa Y, Oishi M, Kita D, Misaki K, Fukui I, Tachibana O $\&$ Nakada M. Contribution of intrasellar pressure elevation to headache manifestation in pituitary adenoma evaluated with intraoperative pressure measurement. Neurosurgery 201984 599-606. (https://doi.org/10.1093/neuros/nyy087)

31 Bussone G, Usai S \& Moschiano F. How to investigate and treat: headache and hyperprolactinemia. Current Pain and Headache Reports 201216 365-370. (https://doi.org/10.1007/s11916-012-0267-x)

32 Kallestrup MM, Kasch H, Østerby T, Nielsen E, Jensen TS \& Jørgensen JO. Prolactinoma-associated headache and dopamine agonist treatment. Cephalalgia 201434 493-502. (https://doi. org/10.1177/0333102413515343)

33 Levy MJ, Matharu MS, Meeran K, Powell M \& Goadsby PJ. The clinical characteristics of headache in patients with pituitary tumours. Brain 2005128 1921-1930. (https://doi.org/10.1093/brain/awh525)

34 Česák T, Poczos P, Adamkov J, Náhlovský J, Kašparová P, Gabalec F, Čelakovský P \& Choutka O. Medically induced CSF rhinorrhea following treatment of macroprolactinoma: case series and literature review. Pituitary 201821 561-570. (https://doi.org/10.1007/s11102-0180907-1)

35 Maiter D \& Delgrange E. Therapy of endocrine disease: the challenges in managing giant prolactinomas. European Journal of Endocrinology 2014170 R213-R227. (https://doi.org/10.1530/EJE-14-0013)

36 Chiloiro S, Giampietro A, Bianchi A \& De Marinis L. Prolactinoma and bone. Current Opinion in Endocrine and Metabolic Research 20183 21-24. (https://doi.org/10.1016/j.coemr.2018.02.006)
37 Di Filippo L, Doga M, Resmini E \& Giustina A. Hyperprolactinemia and bone. Pituitary 202023 314-321. (https://doi.org/10.1007/s11102020-01041-3)

38 Mazziotti G, Chiavistelli S \& Giustina A. Pituitary diseases and bone. Endocrinology and Metabolism Clinics of North America 2015 44 171-180. (https://doi.org/10.1016/j.ecl.2014.10.014)

39 Di Somma C, Colao A, Di Sarno A, Klain M, Landi ML, Facciolli G, Pivonello R, Panza N, Salvatore M \& Lombardi G. Bone marker and bone density responses to dopamine agonist therapy in hyperprolactinemic males. Journal of Clinical Endocrinology and Metabolism 199883 807-813. (https://doi.org/10.1210/jcem.83.3.4674)

40 Ozer FF, Dagdelen S \& Erbas T. Relation of RANKL and OPG levels with bone resorption in patients with acromegaly and prolactinoma. Hormone and Metabolic Research 201850 562-567. (https://doi. org/10.1055/a-0630-1529)

41 Shibli-Rahhal A \& Schlechte J. The effects of hyperprolactinemia on bone and fat. Pituitary 200912 96-104. (https://doi.org/10.1007/ s11102-008-0097-3)

42 Naliato EC, Violante AH, Caldas D, Farias ML, Bussade I, Lamounier Filho A, Loureiro CR, Fontes R, Schrank Y, Loures T et al. Bone density in women with prolactinoma treated with dopamine agonists. Pituitary 200811 21-28. (https://doi.org/10.1007/s11102-007-0064-4)

43 Colao A, Di Somma C, Loche S, Di Sarno A, Klain M, Pivonello R, Pietrosante M, Salvatore M \& Lombardi G. Prolactinomas in adolescents: persistent bone loss after 2 years of prolactin normalization. Clinical Endocrinology 200052 319-327. (https://doi. org/10.1046/j.1365-2265.2000.00902.x)

44 Klibanski A \& Greenspan SL. Increase in bone mass after treatment of hyperprolactinemic amenorrhea. New England Journal of Medicine 1986 315 542-546. (https://doi.org/10.1056/NEJM198608283150903)

45 Ciccarelli E, Savino L, Carlevatto V, Bertagna A, Isaia GC \& Camanni F. Vertebral bone density in non-amenorrhoeic hyperprolactinaemic women. Clinical Endocrinology 198828 1-6. (https://doi. org/10.1111/j.1365-2265.1988.tb01195.x)

46 Klibanski A, Biller BM, Rosenthal DI, Schoenfeld DA \& Saxe V. Effects of prolactin and estrogen deficiency in amenorrheic bone loss. Journal of Clinical Endocrinology and Metabolism 198867 124-130. (https://doi. org/10.1210/jcem-67-1-124)

47 Biller BM, Baum HB, Rosenthal DI, Saxe VC, Charpie PM \& Klibanski A. Progressive trabecular osteopenia in women with hyperprolactinemic amenorrhea. Journal of Clinical Endocrinology and Metabolism 199275 692-697. (https://doi.org/10.1210/ jcem.75.3.1517356)

48 Mazziotti G, Porcelli T, Mormando M, De Menis E, Bianchi A, Mejia C, Mancini T, De Marinis L \& Giustina A. Vertebral fractures in males with prolactinoma. Endocrine 201139 288-293. (https://doi. org/10.1007/s12020-011-9462-5)

49 Mazziotti G, Mancini T, Mormando M, De Menis E, Bianchi A, Doga M, Porcelli T, Vescovi PP, De Marinis L \& Giustina A. High prevalence of radiological vertebral fractures in women with prolactinsecreting pituitary adenomas. Pituitary 201114 299-306. (https://doi. org/10.1007/s11102-011-0293-4)

50 Vestergaard P, Jørgensen JO, Hagen C, Hoeck HC, Laurberg P, Rejnmark L, Brixen K, Weeke J, Andersen M, Conceicao FL et al. Fracture risk is increased in patients with GH deficiency or untreated prolactinomas - a case-control study. Clinical Endocrinology 200256 159-167. (https://doi.org/10.1046/j.0300-0664.2001.01464.x)

51 Webb SM, Crespo I, Santos A, Resmini E, Aulinas A \& Valassi E. MANAGEMENT OF ENDOCRINE DISEASE: Quality of life tools for the management of pituitary disease. European Journal of Endocrinology 2017177 R13-R26. (https://doi.org/10.1530/EJE-17-0041)

52 Cesar de Oliveira Naliato E, Dutra Violante AH, Caldas D, Lamounier Filho A, Rezende Loureiro C, Fontes R, Schrank Y, Gomes de Souza R, Vaisman M, Guerra E et al. Quality of life in women with microprolactinoma treated with dopamine agonists. Pituitary 200811 247-254. (https://doi.org/10.1007/s11102-008-0091-9) 
53 Kars M, van der Klaauw AA, Onstein CS, Pereira AM \& Romijn JA. Quality of life is decreased in female patients treated for microprolactinoma. European Journal of Endocrinology 2007157 133-139. (https://doi.org/10.1530/EJE-07-0259)

54 Leistner SM, Klotsche J, Dimopoulou C, Athanasoulia AP, RoemmlerZehrer J, Pieper L, Schopohl J, Wittchen HU, Stalla GK, Fulda S et al. Reduced sleep quality and depression associate with decreased quality of life in patients with pituitary adenomas. European Journal of Endocrinology 2015172 733-743. (https://doi.org/10.1530/EJE-140941)

55 Vega-Beyhart A, Enriquez-Estrada VM, Bello-Chavolla OY, Torres-Victoria TR, Martínez-Sánchez FD, López-Navarro JM, Pérez-Guzmán MC, Hinojosa-Amaya JM, León-Suárez A, EspinozaSalazar HD et al. Quality of life is significantly impaired in both secretory and non-functioning pituitary adenomas. Clinical Endocrinology 201990 457-467. (https://doi.org/10.1111/cen.13915)

56 Vilar L, Abucham J, Albuquerque JL, Araujo LA, Azevedo MF, Boguszewski CL, Casulari LA, Cunha Neto MBC, Czepielewski MA, Duarte FHG et al. Controversial issues in the management of hyperprolactinemia and prolactinomas - an overview by the Neuroendocrinology Department of the Brazilian Society of Endocrinology and Metabolism. Archives of Endocrinology and Metabolism 201862 236-263. (https://doi.org/10.20945/23593997000000032)

57 Colao A, Di Sarno A, Landi ML, Scavuzzo F, Cappabianca P, Pivonello R, Volpe R, Di Salle F, Cirillo S, Annunziato L et al. Macroprolactinoma shrinkage during cabergoline treatment is greater in naive patients than in patients pretreated with other dopamine agonists: a prospective study in 110 patients. Journal of Clinical Endocrinology and Metabolism 200085 2247-2252. (https://doi.org/10.1210/ jcem.85.6.6657)

58 Lombardi M, Lupi I, Cosottini M, Rossi G, Manetti L, Raffaelli V, Sardella C, Martino E \& Bogazzi F. Lower prolactin levels during cabergoline treatment are associated to tumor shrinkage in prolactin secreting pituitary adenoma. Hormone and Metabolic Research 201446 939-942. (https://doi.org/10.1055/s-0034-1389925)

59 Colao A, Di Sarno A, Landi ML, Cirillo S, Sarnacchiaro F, Facciolli G, Pivonello R, Cataldi M, Merola B, Annunziato L et al. Long-term and low-dose treatment with cabergoline induces macroprolactinoma shrinkage. Journal of Clinical Endocrinology and Metabolism 199782 3574-3579. (https://doi.org/10.1210/jcem.82.11.4368)

60 Vilar L, Freitas Vilar C, Lyra R \& Freitas MC. Pitfalls in the diagnostic evaluation of hyperprolactinemia. Neuroendocrinology 2019 109 7-19. (https://doi.org/10.1159/000499694)

61 Tietz Textbook of Clinical Chemistry and Molecular Diagnostics, 6th ed. 2018.

62 Sassin JF, Frantz AG, Weitzman ED \& Kapen S. Human prolactin: 24-hour pattern with increased release during sleep. Science 1972177 1205-1207. (https://doi.org/10.1126/science.177.4055.1205)

63 Tsur A, Dreyfuss E, Ness-Abramof R, Pollack R \& Cahn A. Role of cannulated prolactin test in evaluation of hyperprolactinemia - a retrospective study. Endocrine Practice 202026 1304-1311. (https://doi. org/10.4158/EP-2020-0260)

64 Sturk A \& Sanders GT. Macro-enzymes: prevalence, composition, detection and clinical relevance. Journal of Clinical Chemistry and Clinical Biochemistry 199028 65-81.

65 Suliman Am STP, Gibney J \& McKenna J. Frequent misdiagnosis and mismanagement of hyperprolactinemic patients before the introduction of macroprolactinemia screening. Clinical Chemistry 200349 1504-1509. (https://doi.org/10.1373/49.9.1504)

66 Fahie-Wilson MN, John R \& Ellis AR. Macroprolactin; high molecular mass forms of circulating prolactin. Annals of Clinical Biochemistry 200542 175-192. (https://doi.org/10.1258/0004563053857969)

67 Gibney J, Smith TP \& McKenna TJ. Clinical relevance of macroprolactin. Clinical Endocrinology 200562 633-643. (https://doi. $\operatorname{org} / 10.1111 / j .1365-2265.2005 .02243 . x)$
68 Fleseriu M, Lee M, Pineyro MM, Skugor M, Reddy SK, Siraj ES \& Hamrahian AH. Giant invasive pituitary prolactinoma with falsely low serum prolactin: the significance of 'hook effect'. Journal of NeuroOncology 200679 41-43. (https://doi.org/10.1007/s11060-005-9108-7)

69 Piketty ML, Prie D, Sedel F, Bernard D, Hercend C, Chanson P \& Souberbielle JC. High-dose biotin therapy leading to false biochemical endocrine profiles: validation of a simple method to overcome biotin interference. Clinical Chemistry and Laboratory Medicine 201755 817-825. (https://doi.org/10.1515/cclm-2016-1183)

70 Aliberti L, Gagliardi I, Dorizzi RM, Pizzicotti S, Bondanelli M, Zatelli MC \& Ambrosio MR. Hyperprolactinemia: still an insidious diagnosis. Endocrine 202172 928-931. (https://doi.org/10.1007/ s12020-020-02497-w)

71 Fleseriu M, Hashim IA, Karavitaki N, Melmed S, Murad MH, Salvatori R \& Samuels MH. Hormonal replacement in hypopituitarism in adults: an Endocrine Society clinical practice guideline. Journal of Clinical Endocrinology and Metabolism 2016101 3888-3921. (https://doi. org/10.1210/jc.2016-2118)

72 Tresoldi AS, Carosi G, Betella N, Del Sindaco G, Indirli R, Ferrante E, Sala E, Giavoli C, Morenghi E, Locatelli M et al. Clinically nonfunctioning pituitary incidentalomas: characteristics and natural history. Neuroendocrinology 2020110 595-603. (https://doi. org $/ 10.1159 / 000503256)$

73 Bona C, Prencipe N, JaffrainRea ML, Carosi G, Lanzi R, Ambrosio MR, Pasquali D, Vettor R, Cannavò S, Ghigo E et al. The prevalence of silent acromegaly in prolactinomas is very low. Journal of Endocrinological Investigation 202144 531-539. (https://doi.org/10.1007/s40618-02001338-x)

74 Balakrishnan CH \& Rajeev H. Correlation of serum prolactin level to Child Pugh scoring system in cirrhosis of liver. Journal of Clinical and Diagnostic Research 201711 OC30-OC33. (https://doi.org/10.7860/ JCDR/2017/24730.10273)

75 Lo JC, Beck GJ, Kaysen GA, Chan CT, Kliger AS, Rocco MV, Chertow GM \& FHN Study. Hyperprolactinemia in end-stage renal disease and effects of frequent hemodialysis. Hemodialysis International: International Symposium on Home Hemodialysis 201721 190-196. (https://doi.org/10.1111/hdi.12489)

76 De Sousa SMC, Meyer EJ, Rankin W, Brautigan PJ, Burt MG \& Torpy DJ. Vasculogenic hyperprolactinemia: severe prolactin excess in association with internal carotid artery aneurysms. Pituitary 201720 676-682. (https://doi.org/10.1007/s11102-017-0833-7)

77 Khawaja NM, Taher BM, Barham ME, Naser AA, Hadidy AM, Ahmad AT, Hamamy HA, Yaghi NA \& Ajlouni KM. Pituitary enlargement in patients with primary hypothyroidism. Endocrine Practice 200612 29-34. (https://doi.org/10.4158/EP.12.1.29)

78 Peuskens J, Pani L, Detraux J \& De Hert M. The effects of novel and newly approved antipsychotics on serum prolactin levels: a comprehensive review. CNS Drugs 201428 421-453. (https://doi. org/10.1007/s40263-014-0157-3)

79 Tewksbury A \& Olander A. Management of antipsychotic-induced hyperprolactinemia. Mental Health Clinician 20166 185-190. (https:// doi.org/10.9740/mhc.2016.07.185)

80 Molitch ME. Dopamine agonists and antipsychotics. European Journal of Endocrinology 2020183 C11-C13. (https://doi.org/10.1530/EJE-200607)

81 Alvarez-Tutor E, Forga-Llenas L, Rodriguez-Erdozain R, Goni-Iriarte MJ, Menendez-Torre E \& Alvarez-Tutor J. Persistent increase of PRL after oral contraceptive treatment. Alterations in dopaminergic regulation as possible etiology. Archives of Gynecology and Obstetrics 1999263 45-50. (https://doi.org/10.1007/s004040050261)

82 Glezer A \& Bronstein MD. Approach to the patient with persistent hyperprolactinemia and negative sellar imaging. Journal of Clinical Endocrinology and Metabolism 201297 2211-2216. (https://doi. org/10.1210/jc.2011-2976)

83 Newey PJ, Gorvin CM, Cleland SJ, Willberg CB, Bridge M, Azharuddin M, Drummond RS, van der Merwe PA, Klenerman P, 
Bountra C et al. Mutant prolactin receptor and familia hyperprolactinemia. New England Journal of Medicine 2013369 2012-2020. (https://doi.org/10.1056/NEJMoa1307557)

84 Bashari WA, Senanayake R, Fernandez-Pombo A, Gillett D, Koulouri O, Powlson AS, Matys T, Scoffings D, Cheow H, Mendichovszky I et al. Modern imaging of pituitary adenomas. Best Practice and Research: Clinical Endocrinology and Metabolism 201933 101278. (https://doi. org/10.1016/j.beem.2019.05.002)

85 Vitale G, Tortora F, Baldelli R, Cocchiara F, Paragliola RM, Sbardella E, Simeoli C, Caranci F, Pivonello R, Colao A et al. Pituitary magnetic resonance imaging in Cushing's disease. Endocrine 201755 691-696. (https://doi.org/10.1007/s12020-016-1038-y)

86 Hagiwara A, Inoue Y, Wakasa K, Haba T, Tashiro T \& Miyamoto T. Comparison of growth hormone-producing and nongrowth hormone-producing pituitary adenomas: imaging characteristics and pathologic correlation. Radiology 2003228 533-538. (https://doi. org/10.1148/radiol.2282020695)

87 Burlacu MC, Maiter D, Duprez T \& Delgrange E. T2-weighted magnetic resonance imaging characterization of prolactinomas and association with their response to dopamine agonists. Endocrine 201963 323-331. (https://doi.org/10.1007/s12020-018-1765-3)

88 Tosaka M, Sato N, Hirato J, Fujimaki H, Yamaguchi R, Kohga H, Hashimoto K, Yamada M, Mori M, Saito N et al. Assessment of hemorrhage in pituitary macroadenoma by $\mathrm{T} 2{ }^{*}$-weighted gradientecho MR imaging. American Journal of Neuroradiology 200728 2023-2029. (https://doi.org/10.3174/ajnr.A0692)

89 Faje A, Chunharojrith P, Nency J, Biller BM, Swearingen B \& Klibanski A. Dopamine agonists can reduce cystic prolactinomas. Journal of Clinical Endocrinology and Metabolism 2016101 3709-3715. (https://doi.org/10.1210/jc.2016-2008)

90 El Euch M, Hentati O, Mahfoudhi M, Bani W, Hamida FB, Jaziri F, Abdelghani KB, Turki S \& Abdallah TB. Extensive sphenoid chordoma mimicking a prolactinoma. Pan African Medical Journal 201933138. (https://doi.org/10.11604/pamj.2019.33.138.12897)

91 Micko ASG, Wöhrer A, Wolfsberger S \& Knosp E. Invasion of the cavernous sinus space in pituitary adenomas: endoscopic verification and its correlation with an MRI-based classification. Journal of Neurosurgery 2015122 803-811. (https://doi.org/10.3171/2014.12.JNS141083)

92 Brochier S, Galland F, Kujas M, Parker F, Gaillard S, Raftopoulos C, Young J, Alexopoulou O, Maiter D \& Chanson P. Factors predicting relapse of nonfunctioning pituitary macroadenomas after neurosurgery: a study of 142 patients. European Journal of Endocrinology 2010163 193-200. (https://doi.org/10.1530/EJE-10-0255)

93 Sanmillán JL, Torres-Diaz A, Sanchez-Fernández JJ, Lau R, Ciller C, Puyalto P \& Gabarrós A. Radiological predictors for extent of resection in pituitary adenoma surgery. A single-center study. World Neurosurgery 2017108 436-446. (https://doi.org/10.1016/j.wneu.2017.09.017)

94 Sarwar KN, Huda MSB, Van de Velde V, Hopkins L, Luck S, Preston R, McGowan BM, Carroll PV \& Powrie JK. The prevalence and natural history of pituitary hemorrhage in prolactinoma. Journal of Clinical Endocrinology and Metabolism 201398 2362-2367. (https://doi. org/10.1210/jc.2013-1249)

95 Molitch ME. Management of medically refractory prolactinoma. Journal of Neuro-Oncology 2014117 421-428. (https://doi.org/10.1007/ s11060-013-1270-8)

96 Alkabbani AG, Mon SY, Hatipoglu B, Kennedy L, Faiman C, Weil RJ $\&$ Hamrahian AH. Is a stable or decreasing prolactin level in a patient with prolactinoma a surrogate marker for lack of tumor growth? Pituitary 201417 97-102. (https://doi.org/10.1007/s11102-013-0473-5)

97 Varlamov EV, Hinojosa-Amaya JM \& Fleseriu M. Magnetic resonance imaging in the management of prolactinomas; a review of the evidence. Pituitary 202023 16-26. (https://doi.org/10.1007/s11102-01901001-6)

98 Eroukhmanoff J, Tejedor I, Potorac I, Cuny T, Bonneville JF, Dufour H, Weryha G, Beckers A, Touraine P, Brue T et al. MRI follow-up is unnecessary in patients with macro-prolactinomas and long-term normal prolactin levels on dopamine agonist treatment. European Journal of Endocrinology 2017 176 323-328. (https://doi.org/10.1530/EJE-16-0897)

99 Schlechte JA. Long-term management of prolactinomas. Journal of Clinical Endocrinology and Metabolism 200792 2861-2865. (https://doi. org/10.1210/jc.2007-0836)

100 Biller BM, Luciano A, Crosignani PG, Molitch M, Olive D, Rebar R, Sanfilippo J, Webster J \& Zacur H. Guidelines for the diagnosis and treatment of hyperprolactinemia. Journal of Reproductive Medicine 1999 44 (Supplement) 1075-1084.

101 McDonald RJ, Levine D, Weinreb J, Kanal E, Davenport MS, Ellis JH, Jacobs PM, Lenkinski RE, Maravilla KR, Prince MR et al. Gadolinium retention: a research roadmap from the $2018 \mathrm{NIH} / \mathrm{ACR} / \mathrm{RSNA}$ Workshop on Gadolinium chelates. Radiology 2018289 517-534. (https://doi.org/10.1148/radiol.2018181151)

102 Thakker RV, Newey PJ, Walls GV, Bilezikian J, Dralle H, Ebeling PR, Melmed S, Sakurai A, Tonelli F, Brandi ML et al. Clinical Practice Guidelines for multiple endocrine neoplasia type 1 (MEN1). Journal of Clinical Endocrinology and Metabolism 201297 2990-3011. (https://doi. org/10.1210/jc.2012-1230)

103 De Laat JM, Dekkers OM, Pieterman CR, Kluijfhout WP, Hermus AR, Pereira AM, van der Horst-Schrivers AN, Drent ML, Bisschop PH, Havekes B et al. Long-term natural course of pituitary tumors in patients with MEN1: results from the Dutch MEN1 study group (DMSG). Journal of Clinical Endocrinology and Metabolism 2015100 3288-3296. (https://doi.org/10.1210/JC.2015-2015)

104 Daly AF, Tichomirowa MA, Petrossians P, Heliövaara E, Jaffrain-Rea ML, Barlier A, Naves LA, Ebeling T, Karhu A, Raappana A et al. Clinical characteristics and therapeutic responses in patients with germ-line AIP mutations and pituitary adenomas: an international collaborative study. Journal of Clinical Endocrinology and Metabolism 201095 E373-E383. (https://doi.org/10.1210/jc.2009-2556)

105 Verhelst J, Abs R, Maiter D, van den Bruel A, Vandeweghe M, Velkeniers B, Mockel J, Lamberigts G, Petrossians P, Coremans P et al. Cabergoline in the treatment of hyperprolactinemia: a study in 455 patients. Journal of Clinical Endocrinology and Metabolism 199984 2518-2522. (https://doi.org/10.1210/jcem.84.7.5810)

106 Eguchi K, Kawamoto K, Uozumi T, Ito A, Arita K \& Kurisu K. Effect of cabergoline, a dopamine agonist, on estrogen-induced rat pituitary tumors: in vitro culture studies. Endocrine Journal 199542 413-420. (https://doi.org/10.1507/endocrj.42.413)

107 Del Dotto P \& Bonucelli U. Clinical pharmacokinetics of cabergoline. Clinical Pharmacokinetics 200342 633-645. (https://doi. org/10.2165/00003088-200342070-00003)

108 dos Santos Nunes V, El Dib R, Boguszewski CL \& Nogueira CR. Cabergoline versus bromocriptine in the treatment of hyperprolactinemia: a systematic review of randomized controlled trials and meta-analysis. Pituitary 201114 259-265. (https://doi. org/10.1007/s11102-010-0290-z)

109 Vroonen L, Jaffrain-Rea ML, Petrossians P, Tamagno G, Chanson P, Vilar L, Borson-Chazot F, Naves LA, Brue T, Gatta B et al. Prolactinomas resistant to standard doses of cabergoline: a multicenter study of 92 patients. European Journal of Endocrinology 2012 167 651-662. (https:// doi.org/10.1530/EJE-12-0236)

110 Iyer P \& Molitch ME. Positive prolactin response to bromocriptine in 2 patients with cabergoline-resistant prolactinomas. Endocrine Practice 201117 e55-e58. (https://doi.org/10.4158/EP10369.CR)

111 Ciccarelli E \& Camanni F. Diagnosis and drug therapy of prolactinoma. Drugs $1996 \mathbf{5 1}$ 954-965. (https://doi. org/10.2165/00003495-199651060-00004)

112 Schlechte J, Dolan K, Sherman B, Chapler F \& Luciano A. The natural history of untreated hyperprolactinemia: a prospective analysis. Journal of Clinical Endocrinology and Metabolism 198968 412-418. (https://doi.org/10.1210/jcem-68-2-412)

113 Gillam MP, Molitch ME, Lombardi G \& Colao A. Advances in the treatment of prolactinomas. Endocrine Reviews 200627 485-534. (https://doi.org/10.1210/er.2005-9998) 
114 Karunakaran S, Page RC \& Wass JA. The effect of the menopause on prolactin levels in patients with hyperprolactinemia. Clinical Endocrinology 200154 295-300. (https://doi.org/10.1046/j.13652265.2001.01190.x)

115 Shimon I, Bronstein MD, Shapiro J, Tsvetov G, Benbassat C \& Barkan A. Women with prolactinomas presented at the postmenopausal period Endocrine 201447 889-894. (https://doi.org/10.1007/s12020-014-0259-1)

116 Santharam S, Tampourlou M, Arlt W, Ayuk J, Gittoes N, Toogood A, Webster R \& Karavitaki N. Prolactinomas diagnosed in the postmenopausal period: clinical phenotype and outcomes. Clinical Endocrinology 201787 508-514. (https://doi.org/10.1111/cen.13399)

117 Santharam S, Fountas A, Tampourlou M, Arlt W, Ayuk J, Gittoes N, Toogood A \& Karavitaki N. Impact of menopause on outcomes in prolactinomas after dopamine agonist treatment withdrawal. Clinical Endocrinology 201889 346-353. (https://doi.org/10.1111/cen.13765)

118 Delgrange E, Daems T, Verhelst J, Abs R \& Maiter D. Characterization of resistance to the prolactin-lowering effects of cabergoline in macroprolactinomas: a study in 122 patients. European Journal of Endocrinology 2009160 747-752. (https://doi.org/10.1530/EJE-09-0012)

119 Giraldi EA \& Ioachimescu AG. The role of dopamine agonists in pituitary adenomas. Endocrinology and Metabolism Clinics of North America 202049 453-474. (https://doi.org/10.1016/j.ecl.2020.05.006)

120 Hage C \& Salvatori R. Predictors of the response to dopaminergic therapy in patients with prolactinoma. Journal of Clinical Endocrinology and Metabolism 2020105 e4558-e5466. (https://doi.org/10.1210/ clinem/dgaa652)

121 Tirosh A, Benbassat C \& Shimon I. Short-term decline in prolactin concentrations can predict future prolactin normalization, tumor shrinkage, and time to remission in men with macroprolactinomas. Endocrine Practice 201521 1240-1247. (https://doi.org/10.4158/ EP15804.OR)

122 Lee Y, Ku CR, Kim EH, Hong JW, Lee EJ \& Kin SH. Early prediction of long-term response to cabergoline in patients with macroprolactinomas. Endocrinology and Metabolism 201429 280-292. (https://doi.org/10.3803/EnM.2014.29.3.280)

123 Kim D, Ku CR, Kim K, Jung H \& Lee EJ. Prolactin $\leq 1$ ng/mL predicts macroprolactinoma reduction after cabergoline therapy. European Journal of Endocrinology 2020182 177-183. (https://doi.org/10.1530/ EJE-19-0753)

124 Biagetti B, Sarria-Estrada S, Ng-Wong YK, Martinez-Saez E, Casteràs A, Cordero Asanza E, Hernandez I, Giralt-Arnaiz M \& Simò R. Shrinkage by the third month predicts long-term response of macroprolactinoma after cabergoline. European Journal of Endocrinology 2021185 587-595. (https://doi.org/10.1530/EJE-210561)

125 Ono M, Miki N, Kawamata T, Makino R, Amano K, Seki T, Kubo O, Hori T \& Takano K. Prospective study of high-dose cabergoline treatment of prolactinomas in 150 patients. Journal of Clinical Endocrinology and Metabolism 200893 4721-4727. (https://doi. org/10.1210/jc.2007-2758)

126 Bancos I, Nannenga MR, Bostwick JM, Silber MH, Erickson D \& Nippoldt TB. Impulse control disorders in patients with dopamine agonist-treated prolactinomas and nonfunctioning pituitary adenomas: a case-control study. Clinical Endocrinology $2014 \mathbf{8 0}$ 863-868. (https://doi.org/10.1111/cen.12375)

127 De Sousa SM, Chapman IM, Falhammar H \& Torpy DJ. Dopatestotoxicosis: disruptive hypersexuality in hypogonadal men with prolactinomas treated with dopamine agonists. Endocrine 201755 618-624. (https://doi.org/10.1007/s12020-016-1088-1)

128 Noronha S, Stokes V, Karavitaki N \& Grossman A. Treating prolactinomas with dopamine agonists: always worth the gamble? Endocrine 201651 205-210. (https://doi.org/10.1007/s12020-015-0727-2)

129 Barake M, Evins AE, Stoeckel L, Pachas GN, Nachtigall LB, Miller KK, Biller BM, Tritos NA \& Klibanski A. Investigation of impulsivity in patients on dopamine agonist therapy for hyperprolactinemia: a pilot study. Pituitary 201417 150-156. (https://doi.org/10.1007/s11102-013-0480-6)
130 Moore TJ, Glenmullen J \& Mattison DR. Reports of pathological gambling, hypersexuality, and compulsive shopping associated with dopamine receptor agonist drugs. JAMA Internal Medicine 2014174 1930-1933. (https://doi.org/10.1001/jamainternmed.2014.5262)

131 Dogansen SC, Cikrikcili U, Oruk G, Ozdemir Kutbay NO, Tanrikulu S, Hekimsoy Z, Hadzalic A, Gorar S, Omma T, Mert M et al. Dopamine agonist-induced impulse control disorders in patients with prolactinoma: a cross-sectional multicenter study. Journal of Clinical Endocrinology and Metabolism 2019 104 2527-2534. (https://doi.org/10.1210/jc.2018-02202)

132 De Sousa SMC, Baranoff J, Rushworth RL, Butler J, Sorbello J, Vorster J, Thompson T, McCormack AI, Inder WJ \& Torpy DJ. Impulse control disorders in dopamine agonist-treated hyperprolactinemia: prevalence and risk factors. Journal of Clinical Endocrinology and Metabolism 2020 105 1-11. (https://doi.org/10.1210/clinem/dgz076)

133 Bachmann-Harildstad G. Diagnostic values of beta-2 transferrin and beta-trace protein as markers for cerebrospinal fluid fistula. Rhinology $20084682-85$.

134 Lam G, Mehta V \& Zada G. Spontaneous and medically induced cerebrospinal fluid leakage in the setting of pituitary adenomas: review of the literature. Neurosurgical Focus 201232 E2. (https://doi.org /10.3171/2012.4.FOCUS1268)

135 Schade R, Andersohn F, Suissa S, Haverkamp W \& Garbe E. Dopamine agonists and the risk of cardiac-valve regurgitation. New England Journal of Medicine 2007356 29-38. (https://doi.org/10.1056/ NEJMoa062222)

136 Zanettini R, Antonini A, Gatto G, Gentile R, Tesei S \& Pezzoli G. Valvular heart disease and the use of dopamine agonists for Parkinson's disease. New England Journal of Medicine 2007 356 39-46. (https://doi.org/10.1056/NEJMoa054830)

137 Roth BL. Drugs and valvular heart disease. New England Journal of Medicine 2007356 6-9. (https://doi.org/10.1056/NEJMp068265)

138 Stiles CE, Tetteh-Wayoe ET, Bestwick J, Steeds RP \& Drake WM. A meta-analysis of the prevalence of cardiac valvulopathy in hyperprolactinemic patients treated with cabergoline. Journal of Clinical Endocrinology and Metabolism 2018 104 523-538. (https://doi. org/10.1210/jc.2018-01071)

139 Stiles CE, Lloyd G, Bhattacharyya S, Steeds RP, Boomla K, Bestwick JP \& Drake WM. Incidence of cabergoline-associated valvulopathy in primary care patients with prolactinoma using hard cardiac endpoints. Journal of Clinical Endocrinology and Metabolism 2021106 e711-e720. (https://doi.org/10.1210/clinem/dgaa882)

140 Ono M, Miki N, Amano K, Kawamata T, Seki T, Makino R, Takano K, Izumi S, Okada Y \& Hori T. Individualized high-dose cabergoline therapy for hyperprolactinemic infertility in women with micro- and macroprolactinomas. Journal of Clinical Endocrinology and Metabolism 201095 2672-2679. (https://doi.org/10.1210/jc.2009-2605)

141 Colao A, Di Sarno A, Cappabianca P, Di Somma C, Pivonello R \& Lombardi G. Withdrawal of long-term cabergoline therapy for tumoral and nontumoral hyperprolactinemia. New England Journal of Medicine 2003349 2023-2033. (https://doi.org/10.1056/ NEJMoa022657)

142 Dekkers OM, Lagro J, Burman P, Jørgensen JO, Romijn JA \& Pereira AM. Recurrence of hyperprolactinemia after withdrawal of dopamine agonists: systematic review and meta-analysis. Journal of Clinical Endocrinology and Metabolism 201095 43-51. (https://doi.org/10.1210/ jc.2009-1238)

143 Xia MY, Lou XH, Lin SJ \& Wu ZB. Optimal timing of dopamine agonist withdrawal in patients with hyperprolactinemia: a systematic review and meta-analysis. Endocrine 201859 50-61. (https://doi.org/10.1007/ s12020-017-1444-9)

$144 \mathrm{Hu}$ J, Zheng X, Zhang W \& Yang H. Current drug withdrawal strategy in prolactinoma patients treated with cabergoline: a systematic review and meta-analysis. Pituitary 201518 745-751. (https://doi.org/10.1007/ s11102-014-0617-2)

145 Kwancharoen R, Auriemma RS, Yenokyan G, Wand GS, Colao A \& Salvatori R. Second attempt to withdraw cabergoline in prolactinomas: 
a pilot study. Pituitary 201417 451-456. (https://doi.org/10.1007/ s11102-013-0525-x)

146 Vilar L, Albuquerque JL, Gadelha PS, Rangel Filho F, Siqueira AM, da Fonseca MM, Viana KF, Gomes BS \& Lyra R. Second attempt of cabergoline withdrawal in patients with prolactinomas after a failed first attempt: is it worthwhile? Frontiers in Endocrinology 2015611. (https://doi.org/10.3389/fendo.2015.00011)

147 Jasim S, Alahdab F, Ahmed AT, Tamhane S, Prokop LJ, Nippoldt TB \& Murad MH. Mortality in adults with hypopituitarism: a systematic review and meta-analysis. Endocrine 201756 33-42. (https://doi. org/10.1007/s12020-016-1159-3)

148 Corona G, Rastrelli G, Di Pasquale G, Sforza A, Mannucci E \& Maggi M. Testosterone and cardiovascular risk: meta-analysis of interventional studies. Journal of Sexual Medicine 201815 820-838. (https://doi. org/10.1016/j.jsxm.2018.04.641)

149 Bonert V. Do nothing but observe microprolactinomas: when and how to replace sex hormones? Pituitary 202023 307-313. (https://doi. org/10.1007/s11102-020-01039-x)

150 Testa G, Vegetti W, Motta T, Alagna F, Bianchedi D, Carlucci C, Bianchi M, Parazzini F \& Crosignani PG. Two-year treatment with oral contraceptives in hyperprolactinemic patients. Contraception $1998 \mathbf{5 8}$ 69-73. (https://doi.org/10.1016/s0010-7824(98)00069-9)

151 Christin-Maître S, Delemer B, Touraine P \& Young J. Prolactinoma and estrogens: pregnancy, contraception and hormonal replacement therapy. Annales d'Endocrinologie 200768 106-112. (https://doi. org/10.1016/j.ando.2007.03.008)

152 Cocks Eschler D, Javanmard P, Cox K \& Geer EB. Prolactinoma through the female life cycle. Endocrine 201859 16-29. (https://doi. org/10.1007/s12020-017-1438-7)

153 Colao A, Vitale G, Cappabianca P, Briganti F, Ciccarelli A, De Rosa M, Zarrilli S \& Lombardi G. Outcome of cabergoline treatment in men with prolactinoma: effects of a 24-month treatment on prolactin levels, tumor mass, recovery of pituitary function, and semen analysis. Journal of Clinical Endocrinology and Metabolism 200489 1704-1711. (https://doi.org/10.1210/jc.2003-030979)

154 Sehemby M, Lila AR, Sarathi V, Shah R, Sankhe S, Jaiswal SK, Ramteke-Jadhav S, Patil V, Shah N \& Bandgar T. Predictors of chronic LH-testosterone axis suppression in male macroprolactinomas with normoprolactinemia on cabergoline. Journal of Clinical Endocrinology and Metabolism 2020105 e4551-e4557. (https://doi.org/10.1210/ clinem/dgaa650)

155 Shimon I, Hirsch D, Tsvetov G, Robenshtok E, Akirov A, Fraenkel M, Eizenberg Y, Herzberg D, Barzilay-Yoseph L, Livner A et al. Hyperprolactinemia diagnosis in elderly men: a cohort of 28 patients over 65 years. Endocrine 201965 656-661. (https://doi.org/10.1007/ s12020-019-01962-5)

156 Bhasin S, Brito JP, Cunningham GR, Hayes FJ, Hodis HN, Matsumoto AM, Snyder PJ, Swerdloff RS, Wu FC \& Yialamas MA. Testosterone therapy in men with hypogonadism: an Endocrine Society clinical practice guideline. Journal of Clinical Endocrinology and Metabolism 2018103 1715-1744. (https://doi.org/10.1210/jc.201800229)

157 Prior JC, Cox TA, Fairholm D, Kostashuk E \& Nugent R. Testosteronerelated exacerbation of a prolactin-producing macroadenoma: possible role for estrogen. Journal of Clinical Endocrinology and Metabolism 198764 391-394. (https://doi.org/10.1210/jcem-64-2-391)

158 Gillam MP, Middler S, Freed DJ \& Molitch ME. The novel use of very high doses of cabergoline and a combination of testosterone and an aromatase inhibitor in the treatment of a giant prolactinoma. Journal of Clinical Endocrinology and Metabolism 200287 4447-4451. (https:// doi.org/10.1210/jc.2002-020426)

159 Duskin-Bitan H \& Shimon I. Prolactinomas in males: any differences? Pituitary 202023 52-57. (https://doi.org/10.1007/s11102 019-01009-y)

160 Ribeiro RS \& Abucham J. Recovery of persistent hypogonadism by clomiphene in males with prolactinomas under dopamine agonist treatment. European Journal of Endocrinology 2009161 163-169. (https://doi.org/10.1530/EJE-09-0084)

161 Webster J, Piscitelli G, Polli A, Ferrari CI, Ismail I, Scanlon MF \& for the Cabergoline Comparative Study Group. A comparison of cabergoline and bromocriptine in the treatment of hyperprolactinemic amenorrhea. New England Journal of Medicine 1994331 904-909. (https://doi.org/10.1056/NEJM199410063311403)

162 Honegger J, Nasi-Kordhishti I, Aboutaha N \& Giese S. Surgery for prolactinomas: a better choice? Pituitary 202023 45-51. (https://doi. org/10.1007/s11102-019-01016-z)

163 Ammirati M, Wei L \& Ciric I. Short-term outcome of endoscopic versus microscopic pituitary adenoma surgery: a systematic review and meta-analysis. Journal of Neurology, Neurosurgery, and Psychiatry $2013 \mathbf{8 4}$ 843-849. (https://doi.org/10.1136/jnnp-2012-303194)

164 Zamanipoor Najafabadi AH, Zandbergen IM, de Vries F, Broersen LHA, van den Akker-van Marle ME, Pereira AM, Peul WC, Dekkers OM, van Furth WR \& Biermasz NR. Surgery as a viable alternative first-line treatment for prolactinoma patients. A systematic review and metaanalysis. Journal of Clinical Endocrinology and Metabolism 2020105 1-10. (https://doi.org/10.1210/clinem/dgz144)

165 Ikeda H, Watanabe K, Tominaga T \& Yoshimoto T. Transsphenoidal microsurgical results of female patients with prolactinomas. Clinical Neurology and Neurosurgery 2013115 1621-1625. (https://doi. org/10.1016/j.clineuro.2013.02.016)

166 Primeau V, Raftopoulos C \& Maiter D. Outcomes of transsphenoidal surgery in prolactinomas: improvement of hormonal control in dopamine agonist-resistant patients. European Journal of Endocrinology 2012166 779-786. (https://doi.org/10.1530/EJE-11-1000)

167 Raverot G, Wierinckx A, Dantony E, Auger C, Chapas G, Villeneuve L, Brue T, Figarella-Branger D, Roy P, Jouanneau E et al. Prognostic factors in prolactin pituitary tumors: clinical, histological, and molecular data from a series of 94 patients with a long postoperative follow-up. Journal of Clinical Endocrinology and Metabolism 201095 1708-1716. (https://doi.org/10.1210/jc.2009-1191)

168 Chanson P \& Maiter D. Prolactinoma. In The Pituitary, 4th ed., ch 16, pp. 467-514. Ed S Melmed. Academic Press, 2017.

169 Kreutzer J, Buslei R, Wallaschofski H, Hofmann B, Nimsky C, Fahlbusch R \& Buchfelder M. Operative treatment of prolactinomas: indications and results in a current consecutive series of 212 patients. European Journal of Endocrinology 2008158 11-18. (https://doi. org/10.1530/EJE-07-0248)

170 Losa M, Mortini P, Barzaghi R, Gioia L \& Giovanelli M. Surgical treatment of prolactin-secreting pituitary adenomas: early results and long-term outcome. Journal of Clinical Endocrinology and Metabolism 200287 3180-3186. (https://doi.org/10.1210/ jcem.87.7.8645)

171 Fatemi N, Dusick JR, Mattozo C, McArthur DL, Cohan P, Boscardin J, Wang C, Swerdloff RS \& Kelly DF. Pituitary hormonal loss and recovery after transsphenoidal adenoma removal. Neurosurgery 200863 709-718; discussion 718. (https://doi.org/10.1227/01. NEU.0000325725.77132.90)

172 Babey M, Sahli R, Vajtai I, Andres RH \& Seiler RW. Pituitary surgery for small prolactinomas as an alternative to treatment with dopamine agonists. Pituitary 201114 222-230. (https://doi.org/10.1007/s11102010-0283-y)

173 Roelfsema F, Biermasz NR \& Pereira AM. Clinical factors involved in the recurrence of pituitary adenomas after surgical remission: a structured review and meta-analysis. Pituitary 201215 71-83. (https:// doi.org/10.1007/s11102-011-0347-7)

174 Bahuleyan B, Menon G, Nair S, Rao BRM, Easwer HV \& Krishna K. Non-surgical management of cystic prolactinomas. Journal of Clinical Neuroscience 200916 1421-1424. (https://doi.org/10.1016/j. jocn.2009.03.024)

175 Ogiwara T, Horiuchi T, Nagm A, Goto T \& Hongo K. Significance of surgical management for cystic prolactinoma. Pituitary 201720 225-230. (https://doi.org/10.1007/s11102-016-0766-6) 
176 Nakhleh A, Shehadeh N, Hochberg I, Zloczower M, Zolotov S, Taher R $\&$ Daoud Naccache D. Management of cystic prolactinomas: a review. Pituitary 201821 425-430. (https://doi.org/10.1007/s11102-018-0888-0)

177 Landolt AM, Keller PJ, Froesch ER \& Mueller J. Bromocriptine: does it jeopardise the result of later surgery for prolactinomas? Lancet 19822 657-658. (https://doi.org/10.1016/S0140-6736(82)92756-8)

178 Menucci M, Quiñones-Hinojosa A, Burger P \& Salvatori R. Effect of dopaminergic drug treatment on surgical findings in prolactinomas. Pituitary 2011 14 68-74. (https://doi.org/10.1007/s11102-010-0261-4)

179 Carija R, Tudor M \& Vucina D. Effect of the preoperative use of dopamine agonists in the postoperative course of prolactinomas: a systematic review. Endocrine Practice 201420 70-74. (https://doi. org/10.4158/EP13165.RA)

180 Jethwa PR, Patel TD, Hajart AF, Eloy JA, Couldwell WT \& Liu JK. Cost-effectiveness analysis of microscopic and endoscopic transsphenoidal surgery versus medical therapy in the management of microprolactinoma in the United States. World Neurosurgery 201687 65-76. (https://doi.org/10.1016/j.wneu.2015.10.090)

181 Sheplan Olsen LJ, Robles Irizarry L, Chao ST, Weil RJ, Hamrahian AH, Hatipoglu B \& Suh JH. Radiotherapy for prolactin-secreting pituitary tumors. Pituitary 201215 135-145. (https://doi.org/10.1007/s11102011-0348-6)

182 Hung YC, Lee CC, Yang HC, Mohammed N, Kearns KN, Nabeel AM, Abdel Karim K, Emad Eldin RM, El-Shehaby AMN, Reda WA et al. The benefit and risk of stereotactic radiosurgery for prolactinomas: an international multicenter cohort study. Journal of Neurosurgery 2019 133 1-10. (https://doi.org/10.3171/2019.4.JNS183443)

183 Cohen-Inbar O, Xu Z, Schlesinger D, Vance ML \& Sheehan JP. Gamma knife radiosurgery for medically and surgically refractory prolactinomas: long-term results. Pituitary 201518 820-830. (https:// doi.org/10.1007/s11102-015-0658-1)

184 Ježková J, Hána V, Kosák M, Kršek M, Liščák R, Vymazal J, Pecen L $\&$ Marek J. Role of gamma knife radiosurgery in the treatment of prolactinomas. Pituitary 201922 411-421. (https://doi.org/10.1007/ s11102-019-00971-x)

185 Tooze A \& Sheehan JP. Neurocognitive changes in pituitary adenoma patients after gamma knife radiosurgery. Journal of Neurosurgery 2018129 (Supplement 1) 55-62. (https://doi.org/10.3171/2018.7. GKS181595)

186 Wolf A, Naylor K, Tam M, Habibi A, Novotny J, Liščák R, MartinezMoreno N, Martinez-Alvarez R, Sisterson N, Golfinos JG et al. Risk of radiation-associated intracranial malignancy after stereotactic radiosurgery: a retrospective, multicenter, cohort study. Lancet: Oncology 201920 159-164. (https://doi.org/10.1016/S14702045(18)30659-4)

187 Gillam MP, Fideleff H, Boquete HR \& Molitch ME. Prolactin excess: treatment and toxicity. Pediatric Endocrinology Reviews 20042 (Supplement 1) 108-114

188 Fideleff HL, Boquete HR, Sequera A, Suárez M, Sobrado P \& Giaccio A. Peripubertal prolactinomas: clinical presentation and longterm outcome with different therapeutic approaches. Journal of Pediatric Endocrinology and Metabolism 200013 261-267. (https://doi org/10.1515/jpem.2000.13.3.261)

189 Colao A, Loche S, Cappa M, Di Sarno A, Landi ML, Sarnacchiaro F, Facciolli G \& Lombardi G. Prolactinomas in children and adolescents. Clinical presentation and long-term follow-up. Journal of Clinical Endocrinology and Metabolism 199883 2777-2780. (https://doi. org/10.1210/jcem.83.8.5001)

190 Steele CA, MacFarlane IA, Blair J, Cuthbertson DJ, Didi M, Mallucci C, Javadpour M \& Daousi C. Pituitary adenomas in childhood, adolescence and young adulthood: presentation, management, endocrine and metabolic outcomes. European Journal of Endocrinology 2010163 515-522. (https://doi.org/10.1530/EJE-10-0519)

191 Yang A, Cho SY, Park H, Kim MS, Kong DS, Shin HJ \& Jin DK. Clinical, hormonal, and neuroradiological characteristics and therapeutic outcomes of prolactinomas in children and adolescents at a single center. Frontiers in Endocrinology 202011 527. (https://doi.org/10.3389/ fendo.2020.00527)

192 Jane JA Jr \& Laws ER Jr. The surgical management of pituitary adenomas in a series of 3,093 patients. Journal of the American College of Surgeons 2001193 651-659. (https://doi.org/10.1016/s10727515(01)01101-2)

193 Perry A, Graffeo CS, Marcellino C, Pollock BE, Wetjen NM \& Meyer FB. Pediatric pituitary adenoma: case series, review of the literature, and a skull base treatment paradigm. Journal of Neurological Surgery: Part B, Skull Base 201879 91-114. (https://doi.org/10.1055/s-0038-1625984)

194 Maheux R, Jenicek M, Cleroux R, Beauregard H, De Muylder X, Gratton NM \& Van Campenhout J. Oral contraceptives and prolactinomas: a case-control study. American Journal of Obstetrics and Gynecology 1982143 134-138. (https://doi.org/10.1016/00029378(82)90641-x)

195 Hulting A-L, Werner S \& Hagenfeldt K. Oral contraceptive steroids do not promote the development or growth of prolactinomas. Contraception 198327 69-73. (https://doi.org/10.1016/0010-7824(83)90057-4)

196 Corenblum B \& Donovan L. The safety of physiological estrogen plus progestin replacement therapy and with oral contraceptive therapy in women with pathological hyperprolactinemia. Fertility and Sterility 199359 671-673. (https://doi.org/10.1016/s0015-0282(16)55819-1)

197 Molitch ME. Endocrinology in pregnancy: management of the pregnant patient with a prolactinoma. European Journal of Endocrinology 2015172 R205-R213. (https://doi.org/10.1530/EJE-14-0848)

198 Klibanski A. Clinical practice. Prolactinomas. New England Journal of Medicine 2010362 1219-1226. (https://doi.org/10.1056/ NEJMcp0912025)

199 O’Sullivan SM, Farrant MT, Ogilvie CM, Gunn AJ \& Milsom SR. An observational study of pregnancy and post-partum outcomes in women with prolactinoma treated with dopamine agonists. Australian and New Zealand Journal of Obstetrics and Gynaecology 202060 405-411. (https://doi.org/10.1111/ajo.13070)

200 Zheng Q, Zhou Q, Li J, Tian Y, Huang H, Yao Q, Wang J \& Zhang J. Placental transfer of bromocriptine in an ex vivo human placental perfusion model. Journal of Maternal-Fetal and Neonatal Medicine 2019 32 1155-1159. (https://doi.org/10.1080/14767058.2017.1402000)

201 Barraud S, Guédra L, Delemer B, Raverot G, Ancelle D, Fèvre A, Jouanneau E, Litré CF, Wolak-Thierry A, Borson-Chazot F et al. Evolution of macroprolactinomas during pregnancy: a cohort study of 85 pregnancies. Clinical Endocrinology 202092 421-427. (https://doi. org/10.1111/cen.14162)

202 Luger A, Broersen LHA, Biermasz NR, Biller BMK, Buchfelder M, Chanson P, Jorgensen JOL, Kelestimur F, Llahana S, Maiter D et al. ESE Clinical Practice Guideline on functioning and nonfunctioning pituitary adenomas in pregnancy. European Journal of Endocrinology 2021185 G1-G33. (https://doi.org/10.1530/EJE-21-0462)

203 Ray JG, Vermeulen MJ, Bharatha A, Montanera WJ \& Park AL. Association between MRI exposure during pregnancy and fetal and childhood outcomes. JAMA 2016316 952-961. (https://doi. org/10.1001/jama.2016.12126)

204 Zoli M, Guaraldi F, Zoia C, La Corte E, Asioli S, Bongetta D, Rustici A \& Mazzatenta D. Management of sellar and parasellar tumors becoming symptomatic during pregnancy: a practical algorithm based on multicenter experience and systematic literature review. Pituitary 202124 269-283. (https://doi.org/10.1007/s11102-020-01107-2)

205 Graillon T, Cuny T, Castinetti F, Courbière B, Cousin M, Albarel F, Morange I, Bruder N, Brue T \& Dufour H. Surgical indications for pituitary tumors during pregnancy: a literature review. Pituitary 2020 23 189-199. (https://doi.org/10.1007/s11102-019-01004-3)

206 Kuhn E, Weinreich AA, Biermasz NR, Jorgensen JOL \& Chanson P. Apoplexy of microprolactinomas during pregnancy. Report of five cases and review of the literature. European Journal of Endocrinology 2021 185 99-108. (https://doi.org/10.1530/EJE-21-0145)

207 Lebbe M, Hubinont C, Bernard P \& Maiter D. Outcome of 100 pregnancies initiated under treatment with cabergoline in 
hyperprolactinaemic women. Clinical Endocrinology 201073 236-242. (https://doi.org/10.1111/j.1365-2265.2010.03808.x)

208 Auriemma RS, Perone Y, Di Sarno A, Grasso LF, Guerra E, Gasperi M, Pivonello R \& Colao A. Results of a single-center observational 10-year survey study on recurrence of hyperprolactinemia after pregnancy and lactation. Journal of Clinical Endocrinology and Metabolism 201398 372-379. (https://doi.org/10.1210/jc.2012-3039)

209 Sant'Anna BG, Musolino NRC, Gadelha MR, Marques C, Castro M, Elias PCL, Vilar L, Lyra R, Martins MRA, Quidute ARP et al. A Brazilian multicentre study evaluating pregnancies induced by cabergoline in patients harboring prolactinomas. Pituitary 202023 120-128. (https:// doi.org/10.1007/s11102-019-01008-z)

210 Raymond JP, Goldstein E, Konopka P, Leleu MF, Merceron RE \& Loria Y. Follow-up of children born of bromocriptine treated mothers. Hormone Research 198522 239-246. (https://doi. org/10.1159/000180100)

211 Glezer A \& Bronstein MD. Prolactinomas, cabergoline, and pregnancy. Endocrine 201447 64-69. (https://doi.org/10.1007/s12020-014-0334-7)

212 Domingue ME, Devuyst F, Alexopoulou O, Corvilain B \& Maiter D. Outcome of prolactinoma after pregnancy and lactation: a study on 73 patients. Clinical Endocrinology 201480 642-648. (https://doi. $\operatorname{org} / 10.1111 /$ cen.12370)

213 Greenman Y. Prolactinomas and menopause: any changes in management? Pituitary 202023 58-64. (https://doi.org/10.1007/ s11102-019-00998-0)

214 Clevenger CV, Chang WP, Ngo W, Pasha TL, Montone KT \& Tomaszewski JE. Expression of prolactin and prolactin receptor in human breast carcinoma. Evidence for an autocrine/paracrine loop. American Journal of Pathology 1995146 695-705.

215 Karayazi Atıcı Ö, Govindrajan N, Lopetegui-Gonzalez I \& Shemanko CS. Prolactin: a hormone with diverse functions from mammary gland development to cancer metastasis. Seminars in Cell and Developmental Biology 2021114 159-170. (https://doi. org/10.1016/j.semcdb.2020.10.005)

216 Tworoger SS, Eliassen AH, Zhang X, Qian J, Sluss PM, Rosner BA \& Hankinson SE. A 20-year prospective study of plasma prolactin as a risk marker of breast cancer development. Cancer Research $2013 \mathbf{7 3}$ 4810-4819. (https://doi.org/10.1158/0008-5472.CAN-13-0665)

217 Gabrielson M, Ubhayasekera K, Ek B, Andersson Franko M, Eriksson M, Czene K, Bergquist J \& Hall P. Inclusion of plasma prolactin levels in current risk prediction models of premenopausal and postmenopausal breast cancer. JNCI Cancer Spectrum 20182 pky055. (https://doi. org/10.1093/jncics/pky055)

218 Dekkers OM, Ehrenstein V, Bengtsen M, Farkas DK, Pereira AM, Sørensen HT \& Jørgensen JO. Breast cancer risk in hyperprolactinemia: a population-based cohort study and meta-analysis of the literature. European Journal of Endocrinology 2015173 269-273. (https://doi org/10.1530/EJE-15-0282)

219 Pottegard A, Lash TL, Cronin-Fenton D, Ahern TP \& Damkier P. Use of antipsychotics and risk of breast cancer: a Danish nationwide case-control study. British Journal of Clinical Pharmacology 201884 2152-2161. (https://doi.org/10.1111/bcp.13661)

220 Chang SC, Chen CH \& Lu ML. Cabergoline-induced psychotic exacerbation in schizophrenic patients. General Hospital Psychiatry 200830 378-380. (https://doi.org/10.1016/j. genhosppsych.2007.11.002)

221 Tollin SR. Use of the dopamine agonists bromocriptine and cabergoline in the management of risperidone-induced hyperprolactinemia in patients with psychotic disorders. Journal of Endocrinological Investigation 200023 765-770. (https://doi. org/10.1007/BF03345068)

222 Allard L, Albarel F, Bertherat J, Caron PJ, Cortet C, Courtillot C, Delemer B, Jublanc C, Maiter D, Nunes ML et al. Efficacy and safety of dopamine agonists in patients treated with antipsychotic and presenting a macroprolactinoma. European Journal of Endocrinology 2020183 221-231. (https://doi.org/10.1530/EJE-20-0125)
223 Schlechte J, el-Khoury G, Kathol M \& Walkner L. Forearm and vertebral bone mineral in treated and untreated hyperprolactinemic amenorrhea. Journal of Clinical Endocrinology and Metabolism 198764 1021-1026. (https://doi.org/10.1210/jcem-64-5-1021)

224 Naliato EC, Farias ML, Braucks GR, Costa FS, Zylberberg D \& Violante AH. Prevalence of osteopenia in men with prolactinoma. Journal of Endocrinological Investigation 200528 12-17. (https://doi. org/10.1007/BF03345523)

225 D'Sylva C, Khan T, Van Uum S \& Fraser LA. Osteoporotic fractures in patients with untreated hyperprolactinemia vs. those taking dopamine agonists: a systematic review and meta-analysis. Neuro Endocrinology Letters 201536 745-749.

226 Iacovazzo D \& De Marinis L. Treatment of hyperprolactinemia in post-menopausal women: pros. Endocrine 201548 76-78. (https://doi. org/10.1007/s12020-014-0377-9)

227 Molitch ME. Dopamine resistance of prolactinomas. Pituitary 20036 19-27. (https://doi.org/10.1023/a:1026225625897)

228 Maiter D. Management of dopamine agonist-resistant prolactinoma. Neuroendocrinology 2019109 42-50. (https://doi org/10.1159/000495775)

229 Souteiro P \& Karavitaki N. Dopamine agonist resistant prolactinomas: any alternative medical treatment? Pituitary 202023 27-37. (https:// doi.org/10.1007/s11102-019-00987-3)

230 Araujo C, Marques O, Almeida R \& Santos MJ. Macroprolactinomas: longitudinal assessment of biochemical and imaging therapeutic responses. Endocrine 201862 470-476. (https://doi.org/10.1007/ s12020-018-1703-4)

231 Vermeulen E, D’Haens J, Stadnik T, Unuane D, Barbe K, Van Velthoven V \& Gläsker S. Predictors of dopamine agonist resistance in prolactinoma patients. BMC Endocrine Disorders 202020 68. (https:// doi.org/10.1186/s12902-020-0543-4)

232 Del Gatto V, Bima C, Chiloiro S, Giampietro A \& Bianchi A. Use of 111In-pentetreotide scintigraphy for diagnosis and management of resistant macroprolactinoma. Endocrine 201860 532-534. (https://doi. org/10.1007/s12020-017-1486-z)

233 Fusco A, Lugli F, Sacco E, Tilaro L, Bianchi A, Angelini F, Tofani A, Barini A, Lauriola L, Maira G et al. Efficacy of the combined cabergoline and octreotide treatment in a case of a dopamine-agonist resistant macroprolactinoma. Pituitary 201114 351-357. (https://doi. org/10.1007/s11102-008-0162-y)

234 Sosa-Eroza E, Espinosa E, Ramírez-Rentería C, Mendoza V, Arreola R $\&$ Mercado M. Treatment of multiresistant prolactinomas with a combination of cabergoline and octreotide LAR. Endocrine 201861 343-348. (https://doi.org/10.1007/s12020-018-1638-9)

235 Trouillas J, Delgrange E, Wierinckx A, Vasiljevica A, Jouanneaua E, Burman P \& Raverot G. Clinical, pathological, and molecular factors of aggressiveness in lactotroph tumours. Neuroendocrinology 2019109 70-76. (https://doi.org/10.1159/000499382)

236 McCormack A, Dekkers OM, Petersenn S, Popovic V, Trouillas J, Raverot G, Burman P \& ESE Survey Collaborators. Treatment of aggressive pituitary tumours and carcinomas: results of a European Society of Endocrinology (ESE) survey 2016. European Journal of Endocrinology 2018178 265-276. (https://doi.org/10.1530/EJE-170933)

237 Giuffrida G, Ferraù F, Laudicella R, Cotta OR, Messina E, Granata F, Angileri FF, Vento A, Alibrandi A, Baldari S et al. Peptide receptor radionuclide therapy for aggressive pituitary tumors: a monocentric experience. Endocrine Connections 20198 528-535. (https://doi. org/10.1530/EC-19-0065)

238 Sinha S, Sharma BS \& Mahapatra AK. Microsurgical management of prolactinomas-clinical and hormonal outcome in a series of 172 cases. Neurology India 201159 532-536. (https://doi.org/10.4103/00283886.84332

239 Shimon I, Sosa E, Mendoza V, Greenman Y, Tirosh A, Espinosa E, Popovic V, Glezer A, Bronstein MD \& Mercado M. Giant prolactinomas larger than $60 \mathrm{~mm}$ in size: a cohort of massive and aggressive 
prolactin-secreting pituitary adenomas. Pituitary 201619 429-436. (https://doi.org/10.1007/s11102-016-0723-4)

240 Qu X, Wang M, Wang G, Han T, Mou C, Han L, Jiang M, Qu Y, Zhang M, Pang Q et al. Surgical outcomes and prognostic factors of transsphenoidal surgery for prolactinoma in men: a single-center experience with 87 consecutive cases. European Journal of Endocrinology 2011164 499-504. (https://doi.org/10.1530/EJE-10-0961)

241 Amar AP, Couldwell WT, Chen JC \& Weiss MH. Predictive value of serum prolactin levels measured immediately after transsphenoidal surgery. Journal of Neurosurgery 200297 307-314. (https://doi. $\operatorname{org} / 10.3171 /$ jns.2002.97.2.0307)
242 Casanueva FF, Barkan AL, Buchfelder M, Klibanski A, Laws ER, Loeffler JS, Melmed S, Mortini P, Wass J, Giustina A et al. Criteria for the definition of Pituitary Tumor Centers of Excellence (PTCOE): a pituitary society statement. Pituitary 201720 489-498. (https://doi. org/10.1007/s11102-017-0838-2)

243 Molitch ME, Findling JW \& Clemmons DR. Excellence in the treatment of patients with pituitary tumors. Pituitary 201821107. (https://doi.org/10.1007/s11102-017-0848-0)

244 Honegger J \& Grimm F. The experience with transsphenoidal surgery and its importance to outcomes. Pituitary 201821 545-555. (https:// doi.org/10.1007/s11102-018-0904-4)

Received 21 September 2021

Revised version received 23 December 2021

Accepted 6 January 2022 